\title{
ENTRETIENS AVEC CINQ ÉCRIVAINES ROUMAINES DE LANGUE FRANÇAISE
}

\author{
1. CRISTIANA ESO
}

\author{
Dan BURCEA ${ }^{1}$ \\ https://doi.org/10.52744/9786062613242.13
}

Résumé : Cristiana Eso est une poète et artiste franco-roumaine née à Constanta en Roumanie, et émigrée à l'âge de 15 ans en France. Après un master en littérature française à la Faculté des Lettres de Nancy, elle suit des études de chant classique au Conservatoire de la capitale lorraine. Elle a publié plusieurs recueils de poésie en roumain ou bilingues, et elle est membre de l'Union des écrivains de Roumanie. Ce chapitre contient deux interviews avec l'écrivaine franco-roumaine.

Mots-clés : Cristiana Eso ; Écrivaine franco-roumaine ; Interviews.

Abstract: Cristiana Eso is a Franco-Romanian poet and artist born in Constanta, Romania and emigrated at the age of fifteen to France. After earning a master's degree in French literature at the Faculty of Letters of Nancy, she studied classical singing at the Lorraine Conservatory. She has published several collections of poetry in Romanian or in bilingual editions and she is a member of the Writers' Union of Romania. This chapter contains two interviews with her.

Keywords: Cristiana Eso; Franco-Romanian Writer; Interviews.

\section{Introduction}

Cristiana Eso est une poète et artiste francoroumaine née à Constanta, en Roumanie, et emigrée à l'âge de 15 ans en France. Après un master en littérature française à la Faculté de lettres de Nancy, elle suit des études de chant classique au Conservatoire de la capitale lorraine. Actuellement, elle est choriste dans le chœur de l'Opéra de Limoges.

Elle a publié plusieurs recueils de poésie en roumain ou bilingues : Carte pentru Oma El (2001), Ordinea precisă a întâmplării. La mécanique du hasard (2005), Inălțarea. L'assomption (2006) aux

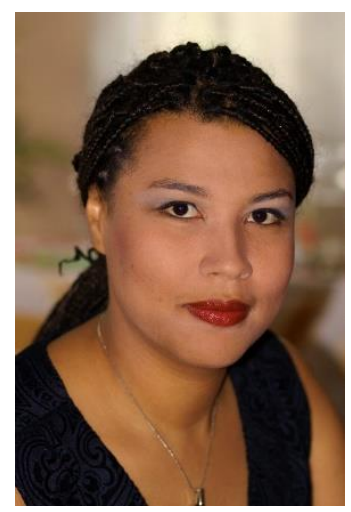
Éditions Ex Ponto.

${ }^{1}$ Critique littéraire français d'origine roumaine,dmburcea@gmail.com 
Le recueil La Mécanique du hasard la révèle comme « un espoir de la poésie roumaine » (Alex Ștefănescu). En 2009, elle devient membre de Uniunea scriitorilor din România.

En 2019, elle a publié le recueil Artisans de l'invisible. Artizanii invisibilului chez Marsa éditions.

\section{Interview. Cristiana Eso : «Ce que nous apprenons enfants reste immuablement gravé dans notre esprit et notre cour 》}

Lorsqu'elle publie en 2001 son premier volume de poésies, «Carte pentru Oma El » ["Livre pour Oma El »], Cristiana Eso mise sur cet ange qu'elle semble fréquenter pour rendre compte de sa sensibilité et de son sens appuyé de la métaphore. Le livre reçoit le Prix Ovidius de l'Union des écrivains roumains et ouvre la carrière de cette francoroumaine qui sublimera son univers poétique dans deux autres volumes, bilingues cette fois : "Ordinea precisă a întâmplării - La Mécanique du hasard » (2004 - Prix Ex Ponto), et " Înălțarea - L'Assomption », (2006). "La Mécanique du hasard » la révèle comme " un espoir de la poésie roumaine » (Alex Ștefănescu). En 2009, elle devient membre de la Société des écrivains roumains. Le belcanto lui donnera par la suite l'occasion de partager son temps entre le travail de la scène en tant qu'artiste des chœurs de l'Opéra de Limoges et l'écriture. Entre 2011 et 2015, elle signe des spectacles musicaux (« Le livre roumain des quatre saisons », "La chaise enchanteresse », " Moi jeune Vlad III dit Dracula ») et participe à des nombreux festivals ainsi qu'à des manifestations multiculturelles et transdisciplinaires.

Il était donc plus que naturel de lui demander ce que représente pour elle être écrivain et artiste d'origine roumaine et d'expression française. Voici sa réponse :

Ce que nous apprenons enfants reste immuablement gravé dans notre esprit et notre cœur. Je suis née en Roumanie et je ne peux pas oublier mes premiers auteurs : Eminescu, Arghezi, plus tard Bacovia, Blaga, Stănescu. Établie en France, j’ai naturellement rapproché, durant mes études littéraires, mes deux cultures et ressenti pleinement leur essence commune et les contrastes de leurs richesses sororales.

Mais, visiblement, il fallait que je ressente autrement le mot. Le Conservatoire m'a ouvert alors de nouvelles perspectives. J'ai vu dans l'accord entre langage et musique l'aboutissement de mes recherches. Ce furent des expériences diverses et divergentes : poésie bilingue francoroumaine, musique de chambre d'Enescu ou de Debussy, poésie sonore fantasque, mélodies sans sémantique arrêtée, mais au combien et immédiatement signifiante à l'auditoire, restant toujours dans le plaisir 
des sens, à la recherche des nouvelles significations. Quel surprenant péché de gourmandise artistique : chanter, réciter, traduire, écrire !

Je me souviens comment je recherchais dans le français que j'apprenais à mes quinze ans, le parfum originel et rassurant de mon enfance. J'étais déjà consciente que notre ancêtre linguistique commun, le latin, m'offrait l'assurance d'une forme particulière de fraternité faisant écho à celle affirmée si clairement dans la devise de ma nouvelle patrie. J'avais la liberté d'évoquer ma culture native à la bienveillante curiosité de mes nouveaux compatriotes. J'y ai rajouté la fierté d'exprimer mon appartenance à un héritage commun. Après avoir publié en roumain, je me suis lancé le défi d'écrire en français, cette langue qui me paraissait si difficile à mon arrivée.

Dans un autre registre, j'ai vu avec quelle aisance la musique reflète l'âme d'une culture, et avec quelle facilité elle gomme la tristesse, l'éloignement, les barrières. Je me rappelle qu'après un concert à l'opéra où j'avais chanté une mélodie d'Alfred Alessandrescu sur un poème de Musset, une personne du public m'a demandé si le compositeur n'était pas l'un des élèves de Paul Dukas, tant était évidente pour elle l'affinité entre les deux compositeurs, et fort le lien culturel et historique entre la Roumanie et la France.

À mes yeux, le plus naturel reste le plus touchant : un enfant pleuret-il, gazouille-t-il différemment, selon sa nationalité ? Je suis toujours émue d'entendre la berceuse d'une mère quelle que soit sa langue. La musique m'a démontré l'existence d'une rassurante continuité, la possibilité de toucher spontanément la sensibilité, une promesse d'une solidarité.

Si le roumain m'a ouvert les portes du monde, dans sa première appropriation et compréhension, c'est le français qui a structuré ma pensée adulte. En écrivant et en chantant, je m'attache à mettre en « harmonie » les opposés, à être de « concert » avec mes semblables, à « m'accorder » au monde par les mots, et par-delà les mots.

Je suis une artiste lyrique qui retient par la plume l'enchantement d'une parole fugace, un écrivain qui apprivoise dans la musique les mots français et roumains qu'elle aime, peut-être comme un alchimiste, dans le plaisir d'une belle aventure.

\section{Cristiana Eso : « Le poète révèle la place que nous avons dans l'architecture du monde $»^{2}$}

Cristiana Eso fait partie de ces artistes dont les multiples facettes rendent difficile toute tentative de définir l'étendue de leurs talents. En

${ }^{2}$ Cristiana Eso, Artisans de l'invisible - Artizanii Invizibilului, Poésie, Texte bilingue français-roumain, Marsa Éditions, 2019, 105 pages. 
tant que musicienne et poète, elle embrasse le monde avec un regard renouvelé, capable de saisir ce qu'elle appelle dans son dernier volume de poésies, Artisans de l'invisible, " un bonheur bâti à partir de tendres regards ». Qui est donc cette mystérieuse postulante aux grands secrets enfermés dans les « envolées nuptiales des oiseaux » et dans " l'ingénierie du vivant »? Quelles sont les sources culturelles, mythologiques et poétiques qui nourrissent son univers ? Quel trait d'union pourrait-on tirer entre ce volume et les précédents qui sont autant de marques

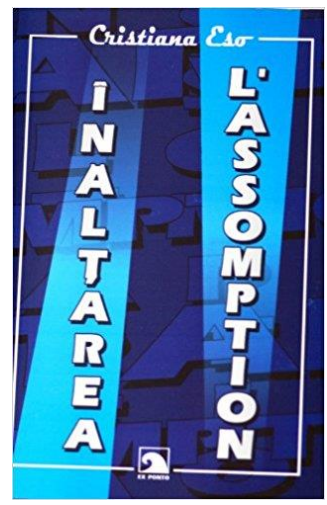
incontestables de son talent ? Cette artiste franco-roumaine avait débuté avec un livre en roumain dédié à un ange, Carte pentru Oma El [Livre pour Oma El] et a publié ensuite deux autres recueils bilingues Ordinea precisă a întâmplării - La mécanique du hasard et Înălțarea L'Assomption.

Nous lui donnons ici la parole pour nous parler de tous ces livres et de la matière secrète qui fait leur substance, surtout de son dernier recueil Artisans de l'invisible - Artizanii invizibilului, publié aux Éditions Marsa en 2019.

Comment vous définiriez-vous en tant que poète ? Je prends ici comme témoin deux de vos formules poétiques : «Mais le poète est des ciseaux/qui tranchent le désespoir » et écrire c'est « voyager vers soi ». Quel sens donner à ces deux métaphores?

L'acte de se positionner comme réverbérant les merveilles du monde fait de chacun de nous un poète. Le premier acte d'écriture est une prise de connaissance du chemin qui va de soi à soi, tout en englobant le monde. Dans son périple, le poète est amené parfois à bouleverser l'ordonnancement des choses, à se repositionner de façon à maintenir l'équilibre entre contingence et beauté, entre inéluctabilité et grâce. Parler d'harmonie me semble déjà un état exceptionnel, presque un miracle. Cette mouvance engendre parfois des états extrêmes, des formes de violence et de sacrifice. Et même dans ces moments, le poète n'échappe pas au principe d'union et de cohésion de l'Univers.

Quelles traces de vos origines roumaines - culturelles, linguistiques ou folkloriques - ont contribué à la naissance de votre univers poétique ?

Mes premières lectures ont été les textes folkloriques et classiques roumains. La petite brebis Mioritza, le monastère d'Arges, le Maître Manole, les contes populaires de Ion Creangă, ou recueillis par Petre Ispirescu, les nouvelles de Barbu Ştefănescu Delavranvcea, les poésies de 


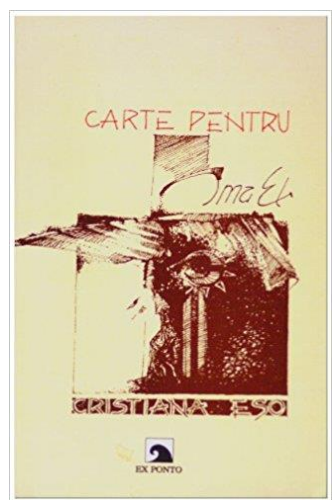

Mihai Eminescu, George Topârceanu, Tudor Arghezi, puis de Nichita Stănescu, la prose de Ioan Slavici, Mihail Sadoveanu, Liviu Rebreanu, et le théâtre de I.L. Caragiale. En grandissant, j'ai découvert Camil Petrescu, Lucian Blaga, Mircea Eliade, Mihail Sebastian, Marin Preda, Emil Cioran, Eugène Ionesco. Enfant, j'ai été marquée par l'imposant ouvrage L'Histoire de la littérature roumaine de George Călinescu. En souriant, je peux vous avouer que le livre de notre bibliothèque me paraissait énorme. Plus tard, pour divers projets et pour mes études à la Faculté de Lettres Modernes de Nancy, j'ai lu les ouvrages critiques d'Alex Stefănescu, de Ştefania et de Marin Mincu, d'Eugen Simion, de Nicolae Manolescu. Ma licence de littérature comparée a pris pour sujet la poésie de Nichita Stănescu et d'Alain Bosquet. J'ai été fascinée par la virtuosité de Nichita Stănescu, (j'entends encore sa voix récitant ses poésies) et mon premier volume en roumain publié, Carte pentru Oma El (Livre pour Oma $E l$ ), traduit l'influence qu'il a eue sur des générations de jeunes poètes. Naturellement, mon premier modèle a été Mihai Eminescu.

Comment avez-vous réussi à réaliser le syncrétisme entre les deux cultures qui ont contribué à votre formation et à la maturation de votre écriture?

Les lectures des grands classiques roumains et français ont été pour moi autant une nécessité qu'un divertissement. J'ai cherché des repères roumains dans le français, lorsque j'en trouvais, je me sentais riche et, le cas contraire, je dépassais la simple démarche de la copie, de la

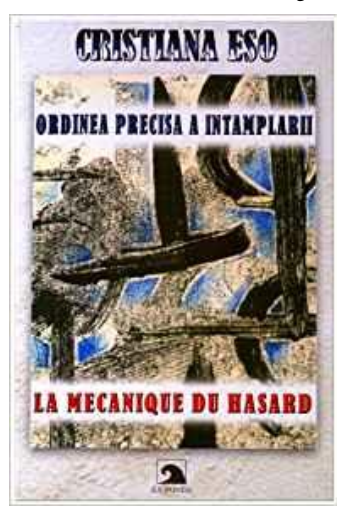
mémorisation des textes, ou encore celle de la traduction. Les détours permettent d'en connaitre davantage. C'est ainsi que les musiques des langues m'ont ouvert les portes de l'imagination ; elles me rassuraient m'offrant un bonheur indéfini et toujours renouvelable à loisir. À l'adolescence, le chant et l'intonation se sont révélés être des outils pour mûrir et comprendre le monde. Au prix d'un travail assidu, ils m'ont permis de connaître la joie du partage du beau. Le phénomène de résonance reste pour moi le media de l'amitié, une forme de manifestation de la vie. Par exemple, je parle de ma jeunesse roumaine près de la Mer Noire, mais lorsque j'interprète une doina de Transylvanie, contrée éloignée de ma ville natale, je parle encore de mon enfance, et cette fois-ci la musique m'exprime de plus belle. 
Vous êtes musicienne. Peut-on dire que la musique vous a aidée dans la création poétique ? De quelle manière ?

J'ai écrit plusieurs spectacles musicaux pour enfants sur le folklore roumain et la Mythologie Roumaine de Romulus Vulcănescu et la Vision Roumaine du Monde d'Ovidiu Papadima m'ont fourni d'intéressantes pistes de réflexion. Du travail d'écriture je suis passée à la mise en scène avec les enfants dans leurs ateliers de pratique musicale. Écrire c'est un peu revivre la magie d'une enfance bercée par l'imaginaire. Qui peut y résister d'ailleurs ? Adultes et écoliers français sont volontiers rentrés dans cet univers inconnu. En expérimentant des aspects plus méconnus de la musique, comme l'improvisation totale ou la poésie sonore, j'ai conçu des textes en associant des sonorités et des phonèmes porteurs de sens pour moi. Les langues se sont mélangées dans une sorte de polyphonie polysémique, ad hoc, éphémère, mais avenante.

Tout en essayant de jeter un regard à la fois sur vos débuts et sur la poésie que vous écrivez aujourd'hui, peut-on parler d'une unité ou, au contraire, d'un éloignement volontaire ? D'une maturation artistique prévisible mais difficile à définir, comme c'est le cas chez presque tous les écrivains? Je pense surtout au lien possible entre «La mécanique du hasard » et « Artisans de l'invisible ».

Je crois qu'on se réécrit toute sa vie. Difficile d'échapper à soi, même par la création. Je pense que le temps permet de vérifier, de comprendre et de s'améliorer, voir récompenser sa jeunesse. J'ai mûri mon écriture, mais je porte un regard à la fois tendre et lucide sur mes premiers poèmes. Le tout prend encore plus de sens à mes yeux, grâce ou à cause du vécu. Des promesses se sont incarnées, des sentiments se sont manifestés, contredisant ou confirmant mes premières projections. J'éprouve cependant le besoin d'explorer d'autres formes poétiques. Entre « La mécanique du hasard » et les "Artisans de l'invisible » sont passées quatorze années. Le lien est toujours présent, soit dans la thématique, soit dans la coloration des textes, mais les vers ont raccourci. Le besoin de consistance, celui d'inviter les références (artistes de la Renaissance et de la période classique, par exemple) ont répondu à l'exigence d'énoncer ce qui compte le plus, offrir ce qui est indispensable.

Je vous propose de nous tourner vers votre dernier livre Artisans de l'invisible.

Conçu en 5 parties, dont la dernière donne le titre de l'ensemble, il se lit comme un voyage à travers des lieux et des époques d'une forte valeur symbolique. Comment s'est construite cette structure et en quoi consiste sa cohérence poétique ? J'avais songé au codex de Voynich, herbier, traité de sciences, œuvre ésotérique, mystérieuse, ce livre illustré 


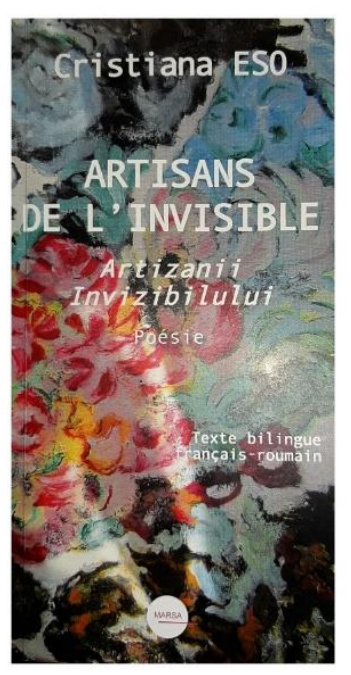

par des dessins énigmatiques, écrit dans une langue méconnue, par un auteur anonyme au XIVe siècle. J'ai organisé mon recueil, tel un carnet de curiosités, d'expérimentations, un ouvrage d'art miniature. Mon premier chapitre Presentia est le constat de la présence du sacré, d'un référent prenant entre autres l'apparence d'une étoile, d'un oiseau, ou de l'être aimé. La partie « Terra Imperatrix » rappelle le lien entre le poète et la Nature, l'errance nécessaire pour tisser du sens. L'homme ne prend conscience de soi que par rapport à un extérieur, un monde qu'aujourd'hui encore nous ressentons et voyons en souffrance. Le troisième cahier «Les saisons n'ont pas de sentiment » / "Anotimpurifără sentiment », brève incursion dans le temps, génère une réflexion sur notre propre nature, sur la temporalité depuis le lever jusqu'au delà du coucher de notre soleil intérieur. Comme dans une équation d'équilibre chimique, un équilibre métaphysique démontre que la beauté contenue dans la neige tombante est la même que celle exhalée par un bouton de rose ou le chant laissé dans le jardin par un rossignol envolé. "Conquérir la forteresse » / " $A$ cuceri cetatea » représente le combat contre l'ignorance et l'inertie, mais aussi contre l'inconséquence et la présomption du connaisseur du « secret des étoiles ». Il y est question de solitude, de constance, de confiance, de persévérance dans son effort. Ultime volet, "Artisans de l'invisible » / " Artizanii invizibilului », rappelle l'ultime produit de la transformation de l'être, la sublimation totale de la matière. Le poète est devenu poème et poursuit son existence dans un ailleurs, la lumière, laissant presque comme leg sa fable mi-confession, mi-inspiration.

Que faudrait-il transmettre à son enfant, sinon la prescription de poursuivre sereinement sa route en respectant la terre et le feu?

Nombreux sont les éléments poétiques auxquels vous faites appel. Je me permets de soumettre deux de ces éléments à votre attention. Le premier est la majesté de la nature (Terra imperatrix) à laquelle « les oiseaux font allégeance/en s'abandonnant au sommeil/dans une soyeuse luminosité », où les arbres se laissent « pister la nostalgie/pour lire les vestiges du bonheur » et tenter de comprendre quel est ce «Modus solvere enigma Mundi ».

Les éléments naturels demeurent la base du travail poétique. L'expérimentation est la maîtresse de tous les maîtres, Leonardo Da Vinci l'a tellement démontré : "L'ingéniosité humaine ne produira jamais une 
invention plus simple et plus belle, car dans la nature rien ne manque et rien n'est superflu », mentionne l'auteur de la Joconde. Le poète pressent que l'homme naît avec l'Univers entier en lui et qu'il subsiste en contemplant l'existant pour s'y reconnaître. Mais il s'agit de ne jamais cesser de rêver, d'inventer la réalité, afin de le découvrir et le décrire correctement. Nos limites se voient ainsi repoussées. Peut-être que la sagesse n'est rien d'autre que demeurer dans l'état amoureux. C'est un autre sens que m'a inspiré la célèbre phrase du Toscan, « Plus on connaît, plus on aime».

Le second est celui de l'art comme ces trois Pietà, ces vitraux toscans ou même ces enluminures qui habitent certains de vos poèmes. Quel est leur rôle dans l'économie symbolique de votre volume?

Les trois Pietà de Michel-Ange représentent le labeur d'une vie d'artiste, destinée pour se dépasser, s'amender, et enfin s'apaiser. Comme les artistes-artisans qui peinent sur leur ouvrage, les poètes persévèrent aussi pour assembler convenablement leurs fragments de vérité. Conquérir la forteresse signifie demeurer serein et lucide, en harmonie avec le monde et dominer la forme brute. Les formes brutes constituent par exemple le bloc de marbre, le morceau de cuir, les vibrations stridentes d'un instrument de musique mal maîtrisé. Il faut alors vaincre la résistance de la matière. Ce chapitre je l'ai placé vers la fin du livre, car au cours de son existence, l'artiste parvient tardivement à se satisfaire de son travail. De même que l'unique acrostiche, les répétitions, les symétries, les collages et divers autres procédés renforcent le plaisir de la découverte et du jeu, les enluminures appartiennent aux manuscrits moyenâgeux et représentent la quintessence du travail d'orfèvre. Le livre s'adresse à l'enfant vénérable, celui qui demeure en nous.

Croyez-vous que la poésie peut encore de nos jours définir le monde ? Et, si oui, de quelle manière ?

Avant les sciences dures, la philosophie... la poésie est le moyen $a$ priori capable de définir le monde. Elle se trouve au commencement et à la fin et peut vivre dans toute chose, sans que la laideur du monde dans sa forme primitive et brutale ne se retrouve jamais en elle. Elle se nourrit du monde et le régénère. La poésie permet d'accoler les choses qui sont faites pour aller de pair. Mais elle est en même temps dans tout et dans son contraire. Pour qu'elle s'exprime, il suffit parfois de supprimer les liens superficiels qui bâillonnent ce qui doit être libre, d'autres fois de bastillonner ce qui ne doit jamais être touché, et quelquefois de canonner pour protéger ce qui doit être défendu. Regarder le monde à travers un rideau de lumière aveuglante, ou encore à travers un arc-en-ciel, c'est encore décrire le réel grâce à la poésie. 
Le dernier poème trace, comme un héritage, le trésor que vous léguez à votre fils. "Puis enfin - écrivez-vous - sois spectateur pour la rose ou le jasmin, et prend place à ton tour dans l'architecture du printemps. Dans la seule vérité qui résiste, fortifie de ta limpidité son délicat parfum, le seyant support de la belle heure et le concret de l'Invisible ». De quelle permanence témoigne ce concret, de quel amour et de quelle nécessaire continuité ?

Le poète révèle la place que nous avons dans l'architecture du monde. La permanence de la vie, de l'espérance vient du fait que nous sommes issus d'une dimension sacrée, que nous portons aussi en nous cette part de mystère et d'absolu. Lorsque nous nous apercevons de cela, notre poésie devient une puissante évidence. 


\title{
2. LAURA T. ILEA
}

\section{Dan BURCEA'}

Résumé : Écrivaine et philosophe roumaine-canadienne, Laura T. Iléa a publié deux romans, un recueil de nouvelles, des études littéraires et une étude sur le philosophe allemand Martin Heidegger. Elle est actuellement professeure de littérature comparée à l'Université Babes-Bolyai, chercheure attachée au SenseLab à l'université de Concordia et membre du Centre de Recherche des Études Littéraires et Culturelles sur la Planétarité de l'Université de Montréal. Ce chapitre contient trois interviews avec l'écrivaine et philosophe roumaine-canadienne.

Mots-clés : Laura T. Iléa ; Écrivaine et Philosophe roumaine-canadienne; Interviews.

\begin{abstract}
Romanian-Canadian writer and philosopher Laura T. Iléa has published two novels, a collection of short stories, literary studies, and a study on the German philosopher Martin Heidegger. She is currently a professor of comparative literature at Babes-Bolyai University, a researcher at SenseLab at Concordia University and member of The Research Center for Planetary Literary and Cultural Studies at the University of Montreal. This paper offers three interviews with Ms. Iléa.
\end{abstract}

Keywords: Laura T. Iléa; Romanian-Canadian Writer; Interviews

\section{Introduction}

Écrivaine et philosophe roumaine-canadienne, Laura T. Iléa a publié deux romans (Cartographie de l'autre monde, Humanitas, Bucarest, 2018 et Les femmes occidentales n'ont pas d'honneur, L'Harmattan, Paris, 2015), un recueil de nouvelles (Est, L'Harmattan, Paris, 2009), des études littéraires parmi lesquelles La littérature canadienne en infrarouge. Le nihilisme féminin (Bucarest, Tracus Arte, 2015), Littérature et scénarios d'aveuglement - Orhan Pamuk, Ernesto

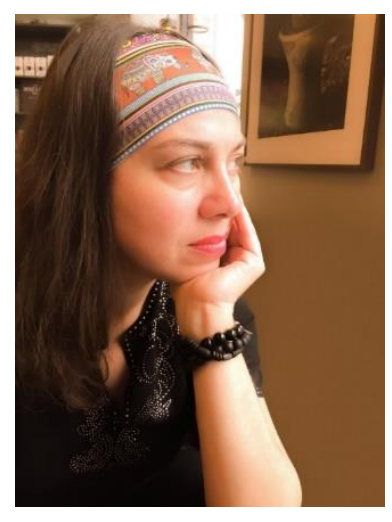

${ }^{1}$ Critique littéraire français d'origine roumaine, dmburcea@gmail.com 
Sabato, José Saramago (Paris, Honoré Champion, 2013) et une étude sur le philosophe allemand Martin Heidegger (La vie et son ombre, Éditions Idea, Cluj-Napoca, 2007). Elle est actuellement professeure de littérature comparée à l'Université Babes-Bolyai, chercheure attachée au SenseLab, Concordia et membre du Centre de Recherche des Études Littéraires et Culturelles sur la Planétarité de l’Université de Montréal.

\section{Interview. LAURA T. ILEA - La langue française comme recherche des « patries intimes »}

\section{Que signifie pour vous être écrivain roumain de langue française?}

L'histoire commence par un jour de juillet où j'ai débarqué pour la première fois à Paris. Dans la langue française. J'avais dix-sept ans. J'y ai passé trois semaines avec quatre heures de sommeil par nuit. Je suis retournée chez moi et je n'y ai plus pensé. Stratégie de survie. Après six mois, j'ai recommencé à rêver. Pour repousser le fantasme aussi loin que possible, j'ai appris l'allemand. J'ai embrassé la philosophie. Jusqu'au jour où, en 1998, au Musée de la littérature de Bucarest, j’ai écouté deux extraits de Sacre de la femme et de La pensée mongole de Marcel Moreau. En présence de l'écrivain. J'avais des choses à lui dire et j'ai passé la nuit à écrire, dictionnaire en main, une lettre maladroite et extatique. Lettre après lettre, la langue française m'a emportée dans la solitude du style. Mais la décision n'était pas encore prise. Elle s'est imposée en 2006, quand j'ai fini mon premier recueil de nouvelles, Est. Encore là, pas tout à fait dans le nouveau monde, celui qui m'a conduite vers la cartographie ironique et stupéfaite du continent américain et vers le cynisme désabusé des Femmes occidentales n'ont pas d'honneur. Jusqu'à mon grand pari d'aujourd'hui, toujours en marge de cette langue, de ne plus sacrifier la beauté malgré l'irrésistible désir de le faire. Rien de plus facile que de détruire la beauté. Tentation à laquelle je ne succomberai pas dans le roman que j'écris. Les longs tête-à-tête que j'ai eus avec la langue française viennent d'un désir de trouver un espace de liberté et de transgresser les tabous de l'intimité. Aucun de mes romans n'est encore publié en roumain. Destin ou chance ? Le jour où cela adviendra, quelque chose de l'ordre de l'indicible disparaîtra.

Que signifie donc pour moi être écrivain roumain de langue française ? Je suis Roumaine quand j'écris en roumain mais est-ce que je deviens Française pour autant quand j'écris en français ? Certainement pas. Le passage entre les deux langues s'est produit dans la même logique de l'hybridité dans laquelle j'ai appris à vivre. Ce n'est pas peu de chose. Mais ce n'est pas facile non plus. Il ne veut pas dire seulement 
multiculturalisme, tolérance, ouverture, mais négociation, ce qu'un écrivain québécois d'origine haïtienne appelle une identité en métaspora, le résultat d'un parcours nomade parsemé de périodes plus ou moins longues de sédentarité. Pour moi la langue française renvoie à une identité en métaspora. Elle est le passage obligé à la recherche des « patries intimes ». Par le fait de continuer à écrire en français, j'affirme donc la primauté du voyage, le cosmopolitisme à l'intérieur de sa propre culture et cette condition étrange que je ne cesserai d'exprimer - la nostalgie dans le cœur même du familier ; la condition d'un homme amalgame. Dont la nostalgie de l'appartenance a été dissoute par la conscience aigüe d'une condition transitoire. Pour moi, le témoignage le plus intime de cette condition est la langue française.

\section{Interview. Laura T. Ilea : " L'honneur est le tabou. L'honneur est le seuil auquel se heurtent les décisions de vie de mes deux personnages ${ }^{2}$}

Avec Les femmes occidentales n'ont pas d'honneur, la Montréalaise Laura T. Ilea nous propose un roman semi-fictionnel autour du thème de l'amour et du renoncement, « deux langues qui s'excluent réciproquement », selon sa narratrice qui écrit rétrospectivement l'histoire d'une séparation annoncée, inévitable, ironique et cruelle. Il s'agit de l'histoire d'amour entre Amran, un homme berbère, et d'une femme slave, qui n'est autre que la narratrice pour qui la quête d'une union amoureuse se révèle interdite et donc impossible, car confrontée à des barrières infranchissables imposées par des traditions et des conceptions de vie irréconciliables. Habituée à scruter les

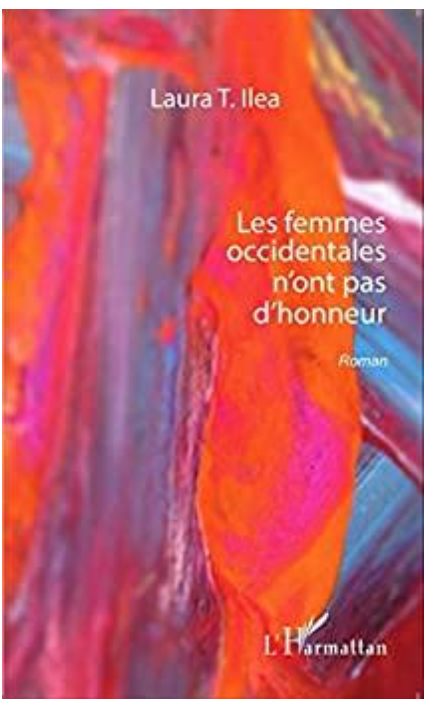
différents espaces géographiques et fictifs pour construire avec les moyens de la littérature une cartographie de l'âme moderne, Laura T. Ilea n'hésite pas à interroger cette fois le monde contemporain sur l'impasse dans laquelle semble s'enliser nos convictions et nos relations, y compris les plus intimes, comme celles de l'amour et de l'union matrimoniale. Roman sur la séparation et la césure entre deux mondes, Les femmes occidentales n'ont pas d'honneur a, en même temps, une portée ontologique sur les blessures anciennes ou à venir de l'être, sur la

2 Interview réalisée par Dan Burcea.

Laura T. Ilea, Les femmes occidentales n'ont pas d'honneur, Éditions L'Harmattan, 212 p. 
construction de l'identité dans un monde où les barrières de l'immigration et les difficultés de l'acculturation n'éludent pas l'énigme intérieur du désir de l'autre et, par voie de conséquence, de l'accomplissement de soi.

Quel sens donner, dès lors, à cet honneur à la fois si chéri et si détesté, comment assumer la dose parfois excessive d'érotisme dont l'héroïne de Laura T. Ilea se pare pour retenir auprès d'elle son amant ? Faut-il penser plus au désir compensatoire d'une Marie Darrieussecq dans Il faut beaucoup aimer les hommes, à l'emprisonnement conjugal d'une Éliette Abécassis dans Et me voici promise à tout homme ou à l'aventure identitaire d'une Karine Tuil dans L'invention de nos vies ? Faut-il se contenter du simple questionnement obsessionnel autour de nos différences pour tenter de définir le monde contemporain? D'ailleurs, ce questionnement nous suffit-il à nous-mêmes pour nous éloigner de nos peurs, pour guérir de nos doutes et éluder un dialogue inconfortable avec nos convictions?

Laura $\mathrm{T}$. Ilea répond ici à toutes ces questions.

Parlons d'abord du titre de votre roman, surtout des multiples connotations que vous donnez tout au long de votre narration au mot honneur (code, preuve, choix, mission, etc.) Quel sens retenir, selon vous?

L'honneur est le tabou. L'honneur est le seuil auquel se heurtent les décisions de vie de mes deux personnages, " la femme occidentale » et l'homme kabyle. Si la femme est prête à sacrifier son honneur de femme, son désir de liberté, ses autofictions et sa quête du bonheur afin de pouvoir vivre, coûte que coûte, cette histoire d'amour vouée d'emblée à l'échec, l'homme, lui, renonce à l'amour, à tout ce que cette relation inattendue aurait pu lui apporter, pour ne pas entacher l'honneur de sa famille, l'honneur de ses ancêtres. Mais aussi parce qu'il est profondément convaincu que les femmes occidentales n'ont pas d'honneur, que dans le mouvement de libération propre à l'Occident, elles ne seraient plus capables d'honorer leurs maris, d'entretenir des relations exclusives avec eux et de ne pas s'adonner aux jeux marécageux de la séduction. Il y a alors une ambiguïté fondamentale quand il s'agit de l'honneur. Pour l'homme, il trace la limite entre la liberté totale d'avant le mariage et le code de vie qu'il embrasse aveuglément une fois la cérémonie de consécration achevée. Pour la femme, c'est le délit de transgression. Elle fait tout (relations à trois, bisexualité, séduction via Skype) afin d'éclater ce code inviolable et de se projeter avec son amoureux dans la chambre des délices où la moralité ne joue plus aucun rôle. Elle rejoue en fait le monde des Mille et une nuits, où le plaisir n'est pas accompagné de culpabilité, où il n'est pas rongé par la barrière perpétuelle entre les deux sexes, barrière la mieux exprimée par la preuve 
de l'honneur. Donc, pour répondre à votre question, parmi les quatre termes que vous avez mentionnés, je choisirais plutôt ceux de code et de preuve, épreuve.

Vous avez déclaré à une autre occasion que votre roman était une semi-fiction, que son sujet vous a été inspiré par une histoire vraie vécue par une personne que vous avez connue. De quoi et de qui s'agit-il ?

Même si j'ai souligné ceci lors du lancement officiel du livre à Montréal, le 28 octobre 2015, vu qu'il s'agissait de rendre publique pour la première fois l'histoire d'une femme que j'ai connue par hasard, qui est devenue mon amie à travers ses confessions, et qui a dû s'enfuir en France à la suite des évènements que je raconte dans le livre, plus le temps passe plus je me rends compte que le roman raconte une histoire universelle, celle des deux mondes qui essaient de s'ajuster l'un à l'autre, mais qui ont du mal à renoncer à leurs interdits et surtout à leurs propres conceptions du bonheur. J'ai tenu à ce que cette histoire devienne publique, moins pour dénoncer l'injustice, mais plutôt pour rendre compte de cette injonction, de cette rupture opérée par certaines traditions qui s'instillent dans le cerveau de ses mâles dominants, en leur dictant la voie à suivre. C'est une soumission presque mystique, comme celle décrite par Michel Houellebecq à la fin de son livre, qui porte ce même titre. C'est la voie de la "vérité ", celle qui est la plus accessible aux humains, la voie de la soumission - la voie embrassée par Amran. Celle que son amoureuse ne comprendra jamais. De là ses méditations sur la cruauté, sur la survie, sur la loi du talion, sur l'amitié et l'amour qui éloignent le roman d'une biographie et le plongent dans la fiction.

Votre personnage déclare, page 104, « j’ai toujours aimé les contretemps ». Peut-on définir l'aventure vécue et racontée par votre narratrice comme une aventure, un accident, un contretemps?

L'affirmation dont vous parlez fait partie du fragment suivant : " On se voyait sur Skype. Je traînais mon portable partout où je marchais. Je me connectais à minuit, avant qu'il attrape le métro qui l'amenait à son trou, son boulot; je me connectais à sept heures du matin, quand il prenait sa pause de midi à Montréal. J'ai toujours aimé les distances. J'ai toujours aimé les histoires. J'ai toujours aimé les contretemps. » Il s'agit alors d'un désir profond de la narratrice, le désir de jouer avec l'interdit. Ce n'est pas seulement une aventure, un accident qui lui tombe dessus. Il est question en égale mesure de sa conception de l'amour, vu comme le désir de prendre la route 66 qui nous mène dans le désert ; la décision, pour une fois, de ne pas exercer de cruauté, un désir de subversion, d'inouï, d'inattendu. C'est d'ailleurs ce qui fait la définition de l'amour, tel 
qu'il est vu par des écrivains que j’admire tels Saramago, Pamuk, Sábato. C'est une dimension initiatrice, un contretemps par rapport à la société contemporaine, qui nous enseigne à tout instant de renoncer à la joie en échange de la sécurité. Mais la sécurité n'apporte pas le bonheur. La sécurité qui sacrifie la joie apporte la dépression, le fléau du monde occidental. L'héroïne de mon roman, en tant que femme occidentale, cherche les solutions subversives, celles qui font éclater les lois immuables de la société. Elle le dit, d'ailleurs : " La meilleure définition de l'amour ? Si je te le demandais soudain, tu prendrais avec moi la route 66 qui nous mènerait dans le désert. Rien d'autre. Une autre définition de l'amour ? Le désir de rester pour une fois, de rester au-delà de l'intoxication du début ; s'abstenir d'exercer la cruauté gratuite qui maintient en vie. $\mathrm{Ne}$ pas exercer de cruauté, c'est déjà une bonne définition de l'amour. » (p. 13) Quant à lui, il veut s'intégrer à tout prix dans tout ce qui est « en ordre ». Il veut résolument sacrifier l'affolement et l'angoisse. Son monde à lui ou le monde occidental - peu importe. Il veut étrangler ce qui est subversif dans l'amour, tout en préservant ses délices. Voici la perspective d'Amran : « Lui, de son côté, devait se purifier, redevenir le mâle astucieux devant sa femme. Il n'y avait qu'une seule entrave à cette démarche fastidieuse : le désir qui brûlait ses intestins. Il fallait qu'il sacrifie tout, qu'il jette tout - mes cahiers, mes photos, mes plats et mes draps et qu'il remette de l'ordre dans sa vie. Qu'il se prépare pour la cérémonie des noces. » (p. 196) Il veut lutter contre le désir, tout en fantasmant sur lui. Ne pas avoir d'honneur signifie finalement assumer le désir comme force vitale, comme mouvement créatif dont le sacrifice serait pire que la mort. En détruisant le désir, on détruit en même temps ce qui fait la force de la vie humaine. Amran préserve son honneur. Il obéit aveuglément. Il se soumet. Est-ce qu'il sera encore capable de connaître le bonheur ? Le livre s'arrête avant que le lecteur puisse se poser cette question.

À l'origine de votre narration se trouve la rencontre, peu après son arrivée à Montréal, de votre narratrice qui veut « connaître des choses inouïes » avec Amran, un homme berbère, séducteur et séduisant. Qui est cet homme?

Amran est l'exotique, le fantasme perpétré par la femme occidentale, le séducteur parfait, une aporie, en fait. La narratrice veut connaître en même temps avec lui l'aventure et la tentation domestique, car elle tente continuellement de lui faire oublier son mariage arrangé, les lois ancestrales qui le tiennent captif avec leur poids immuable. Amran est la projection nostalgique d'une femme qui imagine un jeu de séduction fatal. Amran est l'image pure et dure de la survie, sa cruauté comprise. Il ne fait jamais marche arrière devant ce que la vie lui offre. Il ne fait pas marche arrière non plus quand il s'agit de sacrifier la femme qu'il aime pour des 
raisons de survie. Ce jeu de la cruauté se joue sur plusieurs registres. Il est présent dans les relations de la narratrice avec son ancienne amie communiste : " Ici, en ce maudit monde, disait mon amie à l'époque, on tire le rideau et on étrangle. Sans justification, sans complexe. On s'en tape éperdument. Pas le temps de se morfondre. Dégage. Dégage. Dégage... On écrirait ensemble un livre maudit, un livre noir, un livre banni - Sept règles de survie en Amérique du Nord. Pourquoi survie ? Parce que la survie y est tout. » (p. 148) En ayant vécu avec Amran, la narratrice apprend elle aussi ces sept règles de survie : " Quand le destin ou le hasard... te frappe de toutes ses forces, il n'y a qu'une seule solution : tortille tes fesses dans une danse insolente et brutale. Si ton homme te quitte, cherche-t'en un autre... » (p. 149) Amran est le visage de la cruauté. Le visage de la survie. Celle que la femme devra elle aussi apprendre, afin de pouvoir continuer à vivre après la rupture. Afin d'écrire le livre maudit de leur histoire, Le plaisir interdit.

Loin de mettre inutilement à l'épreuve sa relation, votre héroïne se lance dans une aventure censée « mordre la vie à pleines dents ».

Oui, effectivement. C'est ce que cette relation lui apporte. Le plaisir sans culpabilité, l'expérimentation du désir et de la séduction. L'oubli du poids de l'existence. En ce sens, les deux protagonistes se ressemblent, c'est leur affinité profonde, ce qui explique leur lien irrévérencieux. Tout, à part le désir de " mordre la vie à pleines dents », les sépare. N'empêche que ce désir devient tout aussi puissant que les apories de leurs mondes irréconciliables. Il aurait pu tout chambouler. Mais il ne le fera pas...

Et pourtant, elle n'ignore pas la barrière qui la sépare de son amant : celle d'un engagement, d'un devoir d'honneur envers sa famille restée en Algérie. Quelle est cette barrière ?

Non seulement l'engagement, le devoir d'honneur envers sa famille. Les barrières sont diverses et elles deviennent intenables vers la fin de leur aventure. La façon dont Amran conçoit les relations hommesfemmes, ses préjugés (envers la race jaune, envers les Juifs) et ses codes culturels ( Entre Marc Levy et le Coran, la vie est belle. Si au moins Marc Levy n'était pas juif. Dieudonné aurait cligné de son œil droit en apercevant cette infâme trahison. Quelqu'un qui négocie sa souffrance comme une marchandise n'a aucune dignité », p. 59-60), sa cruauté de chasseur qui quitte femme après femme pour retrouver sa " promise » au bled, ses superstitions concernant l'immaculée conception, la virginité et l'interdit de scruter l'avenir ( "C'est le diable qui nous donne cette envie de connaître les voies mystérieuses de l'avenir. », p. 30). Ce que j'aime dans le pari de la femme, c'est sa folie. Elle veut carrément opérer une « conversion » de son amant. Elle veut qu'il soit capable de convertir 
toutes ces barrières en amour. C'est une folie digne de la tragédie. Une folie que j'ai tenu à souligner dans mon roman, parce que c'est l'élément que nos sociétés extrêmement sécuritaires sacrifient sans cligner d'œil. Et sans un grain de folie, la vie ne vaut pas la peine d'être vécue. C'est le message du roman. Et c'est ce qui constitue son malaise, en même temps, comme le dit très bien Danielle Laurin dans une chronique publiée dans le journal Le Devoir le 23 janvier 2016 (https://www.ledevoir.com/ opinion/chroniques/460876/deux-mondes-irreconciliables). Le malaise vient de toutes les dimensions de l'amour qui y sont explorées : sacrifice de soi, folie, fantasme, séduction, souffrance, pornographie.

Dans ce nouveau paysage, il y a la figure de la mère, femme « redoutable en matière de vengeance », comme la décrit Amran. C'est elle la voix d'un ordre sans appel, celui du mariage avec une vierge restée au pays. Une règle ancestrale, semble-t-il...

Une règle ancestrale, effectivement, mais qu'Amran aurait pu contourner en fin de compte. Il s'agit ici du destin tragique du Maghreb, que j'explore longuement dans le roman, par le biais de la figure de la mère, de la sœur, des oncles et des tantes d'Amran. Des figures troubles, animées par des passions puissantes, qui n'interrogent jamais leur attitude envers les autres. Leurs vérités sont coulées dans du béton. C'est la conséquence d'une vie ayant connu la pauvreté, la révolution et la guerre civile. Tous les membres de la famille d'Amran ont ce côté sombre. N'oublions pas que son père est mort dans des circonstances non-élucidées, peu de temps après son retour de France, où il avait passé trente ans de sa vie, afin de subvenir aux besoins de sa famille, restée au bled. Voilà pourquoi ces personnages nébuleux sont tellement puissants (et effrayants) dans leurs propos : « Sa mère ne sait pas écrire. Sa mère a des propos racistes. Sa mère rumine la vengeance. Elle connait le secret des mariages, du bonheur de ses fils, de ses filles et de ses petits-enfants. Elle sait ce qu'on doit sacrifier. Elle s'est elle-même sacrifiée. Elle ne devra plus jamais être déçue. » (p. 77-78) Le sacrifice et la souffrance représentent donc ce côté sombre. C'est l'incontournable pour Amran. Il ne pourra jamais décevoir sa mère. Ce serait pire que la mort. Et en revenant au destin tragique du Maghreb, je m'en suis rendu compte en parlant avec des hommes et des femmes qui viennent de là-bas, à la suite de la parution de mon roman, qu'il est placé à mi-chemin entre l'Orient et l'Occident. Les hommes (les femmes aussi de plus en plus) aimeraient embrasser la fameuse liberté occidentale, mais ils n'y sont pas prêts pour autant. Cela déclenche des conflits irrémédiables, comme celui qui est décrit dans mon roman : en relation avec des « femmes occidentales », parfois en ayant même des enfants, les hommes font un beau jour tout simplement volte-face, ils quittent tout et se prennent la « vierge » promise dans leur bled natal. Je trouve que c'est un clivage tragique. Que j'ai exploré à fond dans le livre. 
Quelle sera l'attitude du fils devant cette immuable tradition ? Va-t-il prendre le temps d'y réfléchir et d'y répondre ou va-t-il se plier aveuglement à cette tradition ?

Justement, il va se plier aveuglément à cette tradition. Pour les raisons que je viens de décrire : il ne peut pas décevoir sa mère, il ne peut pas trahir la souffrance de son peuple. Son discours est parfois mystique, sans aucun lien avec les faits. C'est pour cela que la perplexité de son amoureuse devant ses actes est totale : "C'était comme un flux mystérieux qui avait pris emprise sur sa vie. Un éclat radieux, un éclat mystique. L'éclat irréel qu'on peut déchiffrer sur le visage des jeunes hommes le jour où ils se jettent dans les flammes, où ils font exploser des voitures, où ils lancent des bombes suicidaires ou tout simplement où ils se dirigent vers leur mariage. Une beauté inouie, comme si l'ange du destin les avait effleurés. » (p. 194)

Que fera votre héroïne devant cette énigme, tout en sachant qu'elle a sa responsabilité de mère envers son fils?

C'est la chose qui a causé le plus de malaise à mes lecteurs. Le fait que dans cette équation passionnelle, la figure du fils est presque inexistante. Il apparaît ici et là, à Zakynthos, en Grèce, après le voyage à Chicago, mais son existence pâlit devant l'explosion de la sexualité reliée aux deux moments. N'oublions pas que les séances de séduction sur Skype se passent à Zakynthos, de même que les fantasmes érotiques de la domination se déroulent à Chicago. La violence du désir sexuel et de l'amour fou l'emporte sur la responsabilité maternelle. C'est le malaise ressenti aussi après avoir vu L'Antéchrist de Lars von Trier. C'est là où les femmes, surtout les femmes, vont décidément exprimer des points de vue contraires : il y en a qui diront que l'attitude de mon personnage féminin est démonique ; il y en a d'autres qui diront qu'une femme sous l'emprise de la passion amoureuse est capable d'aller jusqu'au bout, de tout sacrifier. Bref, mon personnage se livre à cette énigme sans aucune sortie de secours.

Devant ce « tout décidé et tout interdit » qui plonge le couple dans une histoire sans issue, votre narratrice va tenter le tout pour le tout : une séduction totale, débridée et touchant parfois les limites de la pornographie afin de plaire à son homme. Au lieu de choisir comme modèle Shéhérazade, la narratrice ensorceleuse, elle préfère Roxelane, l'esclave, tout en espérant de devenir, comme elle, l'épouse du sultan. Le pari n'est-il pas trop risqué ?

Oui, le pari est très risqué et le lecteur éprouve une sensation d'étouffement. Il se sent gêné par la lutte « passive » de mon personnage, par ses stratégies à la Roxelane. N'oublions pas que cette fameuse Roxelane, « l'esclave », fille d'un prêtre ukrainien, fut une femme exceptionnelle dans 
l'histoire ottomane. Elle avait réussi à instaurer l'exclusivité de la possession sur son mari, le sultan Suleyman. Elle devint la seule femme du harem qui eut le droit d'entretenir des relations intimes avec lui : " D'une ambition démesurée, elle s'est mise à construire systématiquement son empire dans le cœur du sultan, en écartant petit à petit toutes ses concurrentes. Elle se refusa, manigança, tissa des intrigues, se refusa à nouveau au sultan, tua... s'insinua, s'imposa... » (p. 35).

Je ne sais pas si mon héroïne veut devenir « l'épouse du sultan ». Elle veut mener son combat à elle, convertir Amran à l'amour. Mais leurs deux mondes sont irréconciliables. On est gêné, voire paralysé devant ce manque de communication. Cette solution narrative contourne le choix décisionnel du problème, tel qu'il serait envisagé par une « vraie » femme occidentale, adepte du féminisme et des théories postcoloniales. J'ai délibérément choisi la gêne, pour que le lecteur puisse mieux réfléchir à l'incompréhension et au manque de solution inhérent.

Au fil de leur relation, une chose devient de plus en plus évidente : seul le retour au pays et le mariage avec une fille du bled peut donner sens à la vie d'Amran. La fille slave, sa belle occidentale soumise, n'a qu'à se contenter d'un présent incertain et penser à l'inévitable séparation qui les attend. Comment vit-elle ce moment difficile de la rupture ?

Même si je raconte la " chronique d'une séparation annoncée », la femme vit la rupture avec une perplexité croissante. Toutefois, elle va aller jusqu'au bout parce qu'elle veut tout comprendre, les raisons d'agir d'Amran et de son monde. Elle accepte tout, afin de « voir ». Il y en a d'autres qui ont également exploré cette dimension : le personnage de Coetzee dans son livre Disgrace accepte l'abjection et l'humiliation ; le personnage de Marie Darrieussecq dans son dernier roman, Il faut beaucoup aimer les hommes, manque de « réelles convictions » devant un homme " noir » au nom imprononçable, qui est possédé par une idée, celle de tourner un film dans son pays Congo. Mon personnage à moi le dit : " La seule chose que je savais c'était que je voulais être présente jusqu'à la fin. Pour comprendre. Pour voir. Pour revoir. » (p. 198)

Le lecteur comprend rétrospectivement qu'entre le tout décidé, l'infranchissable règle de la tradition et le tout permis, le tout risqué et l'abandon total devant les transgressions, y compris celle de l'honneur d'une femme, que ce pari, donc, est, par sa nature, un pari perdant, surtout pour la femme qui mise là-dessus son honneur, comme vous l'appelez. En cela, sommes-nous dans le cour de la problématique de votre roman qui se situe entre le tout interdit et le tout compris, deux concepts que vous évoquez ailleurs, dans votre ouvrage 
consacré à l'expérience américaine dans la cartographie de l'autre monde?

Excellent résumé du cœur de la problématique du roman. Merci. Depuis toujours j'ai oscillé entre les deux mondes, en essayant de comprendre leurs ressorts et leurs irréconciliables : comme vous le savez, j'ai écrit un premier recueil de nouvelles, paru en 2008 en France, qui s'appelle précisément Est, où je parle de ce pari tragique, le pari sur la fragilité des choses. À l'époque j'avais connu l'Occident par de petites incursions émerveillées, sans le scruter à fond. Effectivement, dans mon ouvrage Cartographie de l'autre monde, j'explore le tout compris du nouveau monde, mes premières perceptions à l'encontre de ce grand continent, des histoires de découverte, d'aventure et de défis technologiques censés renverser les règles de la procréation. Bref, un portrait du nouveau monde vu par quelqu'un qui venait d'atterrir à Montréal et dont les « sept règles de survie » de ce continent lui étaient encore inconnues. Avec Les femmes occidentales, mon premier roman publié, j'ai eu la chance de témoigner d'une histoire qui trace les territoires divergents du tout interdit et du tout compris. Vous avez raison. Je ne crois pas que par sa nature, ce pari soit nécessairement perdant. Mais ceci est ma conviction intime. Je suis quelqu'un qui possède malgré tout un fond humaniste indéfectible. Sauf que dans la littérature je mise sur la « cruauté » des faits. Sans porter de jugements là-dessus. Dans la littérature, j'écoute, je décris, je me laisse emporter par la réflexion. Sans jamais donner mon point de vue.

La critique voit dans votre livre l'expression de la rupture inévitable entre deux modèles de société, orientale et occidentale. Quelle chose sépare-t-il donc aujourd'hui ces deux mondes, notre manque de contact, les clichés véhiculés par de faux prophètes ou la réalité qui ignore tous ces aspects et qui impose sa version des faits?

$\mathrm{Si}$ les deux premières choses que vous mentionnez sont assez évidentes, notamment le manque de contact (ou bien le contact par le biais de maints préjugés) et les clichés véhiculés par de faux prophètes, qui engendrent la violence et l'incompréhension des deux côtés, le troisième élément, la réalité qui ignore tous ces aspects et impose sa version des faits, est essentiel, surtout quand il s'agit de la littérature. C'est ce qu'elle peut faire - éloigner de l'idéologie, éloigner du sous-entendu, éclater les convictions fermes et insinuer l'inépuisable beauté (et cruauté) de la vie. C'est ce que j'ai essayé de faire à travers Les femmes occidentales n'ont pas d'honneur.

S'il y a une seule chose immuable dans votre roman, c'est laquelle? Quel sens et quelle portée lui donner? 
C'est l'amour. C'est la seule chose qui peut chambouler les codes de vie, opérer des conversions et dissoudre l'incompréhension. Avant de juger, même avant de comprendre, il faut d'abord aimer.

\section{Et une chose optimiste?}

La fin du roman. Le fait qu'après la destruction, la douleur et « le manque d'honneur ", la vie est quand même possible. Cela s'applique, espérons-le, à la crise du monde occidental confronté au monde arabe. Sur les débris de cette destruction massive, il y a la possibilité de la continuation. Et non dans la forme de la soumission, comme l'affirme ironiquement Houellebecq dans son livre homonyme, mais dans la forme de la liberté coûte que coûte. D'un amour qui peut opérer des conversions. D'une écoute attentive. C'est la seule qui peut frayer de nouveaux chemins qui éclatent l'aporie. Je m'exprime à travers les mots de la narratrice du roman, qui mélangent la tristesse, l'espoir et la compréhension. Une nouvelle vie est possible après la destruction qui porte le nom d'Amran : « Moi, j’ai finalement lâché prise. J'ai fait un don généreux. Au moins une femme venant de là-bas connaîtrait le plaisir. Sa femme. Grâce à moi. Moi, j'ai fini mes comptes avec cette histoire. Le Libanais n'a rien pu me faire oublier. "Jure-moi sur la tête de ton fils qu'il n'y a personne à part moi." Voilà, maintenant je ne le jure plus. Et cela me rend triste. C'est lui en fin de compte qui a imaginé un monde après moi. Moi, j'ai juste acquiescé. » (p. 207)

\section{Laura T. Iléa : « La littérature est l'état du monde 》}

J'hésite depuis quelques jours à répondre à la proposition d'écrire sur la littérature en temps de pandémie. J'avoue qu'en fermant la porte et en coupant les ponts des médias sociaux, j'oublie pour un instant que cela existe même. Et pourtant, je suis passée par tous les scénarios de cette accélération science-fiction suite à laquelle on est tombé dans l'épidémie de l'affect, après l'épidémie virale. Chaque scénario me semble tour à tour vraisemblable : oui, sans doute, un monde connecté qui a fait éclater l'épidémie de panique, qui a conduit les gouvernements à adopter des mesures restrictives (un tel quorum en faveur des mesures contraignantes n'a jamais été réuni) ; des gouvernements qui ferment des frontières qui ne seront plus rouvertes comme avant - un bon prétexte pour trouver des solutions à des problèmes insolubles. J'ai pensé à l'intoxication média, à la société du spectacle, où un freak show de proportions se déroule à l'échelle planétaire, avec des personnages de premier ordre en vedette Tom Hanks en Australie, M. Trump qui donne la main à un diplomate brésilien, Madonna qui parle de l'égalité de tout le monde devant la maladie, tout fraîchement refaite par des chirurgies plastiques coûteuses. La vitesse ahurissante par laquelle les lunettes captent des catastrophes 
partout - les forêts en Amazonie, les forêts en Australie, ensuite le corona. Â peine est-on sorti d'une catastrophe qu'on est plongé dans une autre. Je me demande comment nous pourrons tenir le rythme.

Tout de suite des analogies livresques. L'aveuglement de Saramago, une prémonition évidente pour la situation présente. Des références qui circulent partout et qui nous parlent du pouvoir du salut de l'art et de la science - Shakespeare qui aurait écrit Le Roi Lear en temps de confinement, Newton qui aurait découvert trois lois fondamentales de la physique dans son auto-isolement pendant la peste, Nancy qui parle d'un trop humain virus, Bruckner et l'impossibilité de rester avec soi. Rien de plus dépressif qu'un monde sans distraction, dit-il en citant Pascal. Bien sûr, la plongée est directe et sans détour vers l'érotisme violent du Décaméron, écrit aussi en temps de peste.

Du coup, je me promets de lire les livres de tous ceux que je devrais lire depuis ô combien de temps - des témoignages de mes trois mondes, que je crains de ne plus pouvoir réintégrer. Moi, avec ma naïveté planétaire, avec mon utopie dont j'ai maintenant la nostalgie. Il ne s'agit pas de moi, je ne veux pas m'exprimer, ce n'est pas une occasion pour un dithyrambe laïque ou pour des figures de style. J'essaie aussi de soustitrer des messages infus pour un monde à venir à mes étudiants pendant les cours en ligne, en leur disant que le grand temps est venu pour le retranchement sur soi. Bref, pour la philosophie, pour l'art et la littérature. Mais ils sont sincères : quoiqu'ils fassent, ils ne peuvent pas s'échapper du grand spectacle. Il est là et il les fascine, avec sa force d'absorption. On se sent vivant en étant dedans.

Et bien sûr, j'admire les amis de loin et de près qui ont décidé de ne pas faire le spectacle. Qui écrivent, continuent leurs projets sans se laisser envahir par l'anxiété et par les images contradictoires qui se déroulent devant nos yeux. Avec nous.

Je protège mes enfants. Je ne veux pas qu'ils développent des réflexes de panique, d'animaux traqués. Je ne sais pas s'ils pourront voyager comme moi.

Je me rends compte que ça ne dépend pas du tout de moi - leur offrir un monde.

Tel ou tel.

Je leur offre mes fictions. Mes idées. Mes rages. Et mon rire.

Je ne veux pas en faire de la littérature.

Ce n'est pas une occasion pour les mots de jaillir.

L'état du monde ne doit pas devenir littérature.

Et pourtant, on ne peut rien faire d'autre qu'en parler. 
5. Laura Ilea în dialog cu Dan Burcea: Romanul meu presupune în egală măsură traversări spațiale și traversări între arhaic şifuturist, între viață şi încercarea de domesticire a morții, între barbarie şi civilizație şi invers, între aparenta civilizație şi barbarie.

De multă vreme, preocupările universitare dar şi literare ale Laurei T. Ilea converg către domeniul nomadismului ca formă de scrutare antropologică a ființei contemporane suspendată între tentația voiajului şi finitudinea cunoaşterii interioare. În această perspectivă se înscrie şi ultimul său roman „Cartografia lumii de dincolo”, apărut anul acesta la Editura Humanitas, în colecția Scriitori români contemporani. Concepută ca o „cartografie imaginară, hieroglifică, greu de descifrat, însă cu atât mai fascinantă", lumea în care evoluează Amalia,

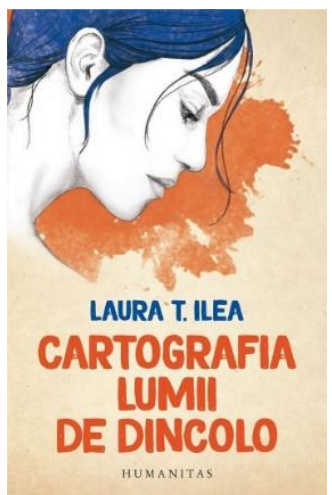
personajul principal al romanului, se întinde pe mai multe continente, fiecare jucând rolul unei revelații a eului său traversat de multiple întrebări. Roman odiseic al unei inevitabile întoarceri la origini, el îşi alimentează suflul vital în lumina unei feminități care se zbate pentru a da viață, scop matern ultim şi necesar. Cine sunt Amalia, Daria, legendara ei bunică, cine sunt bărbații care traversează poveştile acestor femei? Autoarea a avut amabilitatea să ne răspundă în acest pasionant interviu.

Draga Laura, îți propun sa începem discuția noastră cu un quiz asupra titlului cărții tale „Cartografia lumii de dincolo”. Dacă ar fi să alegi din aceste patru semnificații legate de ideea de voiaj, pe care le-ai prefera şi în ce ordine: călătorie; periplu; odisee; traversare?

Interesantă întrebare. Le-aş alege în ordinea următoare: în primul rând traversare, pentru că aceasta implică imediat ideea celor două extremități de traversat - două spații care în principiu se exclud, dar care trebuie să-şi găsească un numitor comun. Apoi aş alege călătoria pentru nonşalanța termenului. Voiajul presupune şi această formă de deresponsabilizare specifică oricărei călătorii, momentului în care aruncăm în urmă greutatea vieții noastre de zi cu zi şi ne îndreptăm, dezgoliți şi lejeri, înspre noi spații de explorat. Apoi l-aş numi odisee pentru că, bănuiesc, un voiaj presupune inevitabil şi acest gest viguros de cucerire a unui nou spațiu, chiar cu prețul de a-ți lăsa acolo pielea, iluziile şi amintirile, cum i s-a întâmplat desigur celui de la care provine acest nume. Şi, nu în cele din urmă, periplu, adică încercuire, revenire uneori obsesivă asupra aceloraşi curiozități, repere, redefinire, replonjare. 


\section{De unde a pornit nevoia scrierii acestui roman pe care tu îl califici în primă instanță de traversare?}

De la traversarea însăşi. Eu însămi am traversat spații divergente în decursul a douăzeci de ani. Însă romanul nu e neapărat o biografie. El presupune în egală măsură traversările succesive ale mai multor personaje: traversări spațiale pentru că frontierele devin poroase; traversări între arhaic şi futurist, între viață şi încercarea de domesticire a morții, între barbarie şi civilizație şi invers, între aparenta civilizație şi barbarie. Cred, aşadar, că romanul s-a născut din nevoia imperioasă pe care am resimțit-o la câțiva ani de la aterizarea pe continentul american în Canada, patria mea de adopție, - de a îmi inventa una, dacă nu mai multe vieți paralele. De a afla ce s-ar fi întâmplat dacă... dacă m-aş fi urcat pe un vapor într-o bună zi ca Daria, bunica Amaliei, şi mi-aş fi condus viața după premoniții, prohibiții, iubiri care schimbă destinul, basme ale tinereții fără bătrânețe care, odată trecută frontiera înapoi, în trecut, aduc dezagregarea şi colapsul memoriei. Dacă m-aş fi pus în pielea Anei Aman, cea care perpetua mitice rețete ale întineririi şi se opunea cu vehemență chirurgiei plastice, şi care a înfruntat-o, la fel de mitic, pe preşedinta consiliului ştiințelor, obsedată, precum sonatul ei soț, de doctrina nemuririi în veac a ideologiei în care credeau. Ce s-ar fi întâmplat dacă maş fi pus în pielea lui Johannes Müller, un german de origine română care conduce un institut de geriatrie la Aachen şi care vrea să-şi iniţieze pacienții în turismul ludic, dar şi atroce, al morții. Iată, aşadar, câteva personaje care sunt urmărite de ideea tinereții fără bătrânețe, fie prin proiectele lor extravagante, fie prin dorința de a lărgi limitele lumii vizibile înspre cartografierea lumii de dincolo.

Romanul tău este dominat de figura Amaliei care pentru mine are multiple fațete. Să vorbim mai întâi de experiența dezrădăcinării pe care o trăieşte. Este această fată care vine dintr-un sat transilvănean, traversând meridianele, o dezrădăcinată?

$\mathrm{Nu}$, nu cred că este o dezrădăcinată. La fel de dezrădăcinată părea a fi şi în satul ei de la poalele muntelui Găina unde supraviețuise un ritual arhaic de măritiş. Ritualul pe care îl descriu acolo nu e decât tangențial românesc - romanul meu nu e un studiu de etnografie. El e împrumutat din stepele Asiei, dar ceea ce mă interesează prin violența lui este de a pune în evidență faptul că ne putem simți la fel de nefamiliari într-o lume care aparent pare familiară. Că ne putem simți în exil, din motive diferite, în propria patrie. Şi că aceasta este o condiție pe care nu se poate să nu o simțim de-a lungul vieții. Fie că suntem confortabili, fie că ne aflăm întro situație care adânceşte şi mai mult acest aspect fundamental al condiției umane - odiseea recuperării de sine trece uneori, inevitabil, prin ani de rătăciri departe de casă. Odiseu, pentru că tot am vorbit de el la început, 
nu era un dezrădăcinat. Era un om care fusese condus prin forța destinului înspre un război care nu îi aparținea sau care îl privea doar prin apartenența la neamul grec. După care, pentru a-şi recăpăta Itaca natală, are nevoie de explorarea lumii de aici şi a celei de dincolo, de rătăciri, ciclopi, Circe, Calypso şi sirene-harpii, pentru a ajunge în sfârşit acasă. Eu nu vorbesc despre dezrădăcinare, ci despre călătorie. Şi aceasta îmi vine poate de la exploratorii spațiului pe care am învățat să-i iubesc în America şi pentru care călătoria reprezintă o stare de a fi şi nu o pierdere de sine: Dany Laferrière în Enigma întoarcerii, unde recuperarea memoriei tatălui se face prin voiajul, mai întâi prin ținuturile înghețate ale Canadei, iar apoi prin cele sufocante ale Haitiului. Catherine Mavrikakis, care în Balada lui Ali Baba poartă urna tatălui mort până în sudul Statelor Unite, la Key West. Să nu mai vorbim de Jack Kerouack, care apare în mod explicit în carte. De Divisadero al lui Michael Ondaatje, de Palatul lunii al lui Paul Auster, care se termină cu o străbatere a Americii de la est la vest, aparent fără un motiv anume. Aceasta am învățat cred pe continentul american: că nu există cunoaştere, întoarcere în trecut sau proiecție în viitor fără mişcare. De aceea personajele mele sunt mereu în mişcare. Deci, pentru a răspunde la întrebarea ta, nu, nu e vorba de dezrădăcinare.

Lumea spre care Amalia porneşte alături de iubitul ei Andrei de voie-de nevoie, dar în orice caz cu brutalitate, este desenată după nişte coordonate neobişnuite. Îți propun să ne oprim mai întâi la cele ale lui Johannes Müller, demn urmaş al Anei Aman şi al promisiunii ei de tinerețe veşnică. Ce ne poți spune despre utopia nebună a acestui om şi a flotei lui, „Anavital"?

Utopia acestui om este cea de a-i iniția pe cei care se prezintă la institutul lui în tainele morții. În afara misteriilor mai vechi, a religiilor mai noi şi a misticismelor dintotdeauna, nu există prea multe căi de inițiere în aceste taine, în lumea în care trăim. E uşor de vorbit despre laicitate sau despre proiecțiile pozitiviste ale lui Yuval Noah Harari atunci când vorbeşte despre dreptul la nemurire, cât se poate de tehnologic, specific vremii noastre. Laicitatea înseamnă separarea laicului de religios, care funcționează atâta vreme cât ființa umană are perfectă autonomie, iar utopia lui Harari s-ar putea foarte bine să fie realizabilă în termeni ştiințifici, însă pentru moment acest teritoriu este încă extrem de înspăimântător. Nici nu ştim dacă el ar trebui eradicat, a demonstrat-o Saramago în Intermitențele morții, în care a imaginat ce s-ar întâmpla dacă într-o bună zi moartea ar dispărea de pe fața pământului. Dar nu despre aceasta e vorba aici. Johannes Müller e un fantast, dar în acelaşi timpel e un om de ştiință. El este cel care a recuperat toate produsele Anei Aman (în realitate Ana Aslan), când aceasta le-a vândut în Germania, după confruntarea cu preşedinta consiliului ştiințelor, desigur Elena 
Ceauşescu. Aşadar, el vrea să-şi iniţieze întreaga lui escadrilă, foşti generali de armată, picați de la universități celebre, oameni care într-o bună zi nu mai vor să facă parte din mascarada adecvării perfecte la prestanță, strălucire şi reuşită socială... vrea aşadar să-i inițieze în regatul morții. Şi cum o face el? Înscenându-le toate catastrofele istorice, expunându-i la toate scenariile răului infuze în această lume. În felul acesta îşi doreşte ca „flota” lui umană să capete perspectivă metafizică, să se desprindă cumva de contingența simplului destin uman individual. E patetic, desigur, ca orice scenariu care încearcă să iasă din cursul firesc al naturii, dar patetismul lui are şi o anume noblețe tragică. La fel ca şi flota lui „Anavital” eşuată pe Rin şi care anunță degradarea ultimă a imperiului fantasmagoric de la Aachen. Quod erat demonstrandum. Singura posibilitate de menținere a vieții, a tinereții veşnice înseamnă, aşadar, posibilitatea de a te menține în flux. Orice altă formulă e sortită eşecului.

\section{Întâlnirea Amaliei cu Armand la Paris pare să-i aducă un moment de calm. Am putea-o califica drept o paranteză lenifiantă?}

Aşa pare la prima vedere după răcirea primei ei iubiri, cea pe care o împărtăşise cu Andrei, violonistul din creierii munților cu care a decis într-o bună zi să-şi ia câmpii, să dezerteze din comunitatea ei tradițională şi să străbată Europa ca doi perpetuatori ai unei tradiții nomade. Vezi, aşadar, că revin mereu la aceste tradiții ale nomadismului, nu doar în America, ci şi în Europa, chiar dacă aici pare că aceste tradiții sunt mereu sortite răcirii şi tăcerii. Poate din cauza unui teritoriu prea bine circumscris, în care parcă nu mai există portițe de scăpare. Întâlnirea lui Armand la Paris, a cercetătorului care imaginează în secret o lume a viitorului care ni se va dezvălui abia la sfârşitul romanului, pare a fi pentru moment o paranteză. Amalia face acolo studii de coregrafie şi urmăreşte îndeaproape întâlnirile iubitului ei cu specimene de limită, cu doctrine ale reproducerii artificiale, cu sinucigaşi notorii care străbat lumea pe aripile insomniei lor, cu tămăduitori bizari ai insomniei. E o lume care pare a circumscrie bizareriile fantasmelor sale anterioare. Numai că tot acolo se întâmplă ceva. Şi anume se întâmplă că fata rămâne însărcinată, în timp ce Armand are oroare de reproducere, vom înțelege de ce la sfârşitul romanului. Aşa că ea rupe din nou legătura cu trecutul ei şi se îndreaptă spre Montreal, nu înainte de a-i spune bărbatului că renunțase la viitorul copil printr-un avort. Armand pleacă la rândul lui la New York pentru a-şi duce la bun sfârşit planul lui de o viaţă, şi anume punerea bazelor ectogenezei - uterul artificial -, neştiind că Amalia se află la Montreal. Vedeți aşadar că în romanul acesta e multă acțiune, decizii bruşte. Am nevoie ca personajele mele să-şi dezvăluie adevărata natură prin acțiunile pe care le fac mai mult chiar decât prin introspecția lor. Desigur noi, urmărindu-i, putem trage concluzii diverse în legătură cu lumea pe care 
ei o plăsmuiesc şi în care ne aflăm şi noi într-o anumită măsură. Însă, în roman simt nevoia ca aceasta să se facă prin acțiune şi mai puțin prin lupa interiorității.

Urmează apoi un voiaj pe care Amalia îl califică de „lunar”. Este vorba de emigrarea ei în Canada în condiții cu totul particulare. Nu călătoreşte singură, ci împreună cu bebeluşul pe care-l poartă. Ce ne poți spune despre integrarea ei în noua lume?

Integrarea în noua lume, voiajul lunar, are întotdeauna de a face cu modul în care e interiorizat spațiul, trecutul şi marginalitatea. Amalia interiorizează spațiul prin călătoria ei, însoțită de Maria, cea care betonează tot ceea ce e sălbatic în America, cu care se deplasează înspre New Orleans, în sud. Aici intervine interiorizarea celei de a doua părți, şi anume trecutul. Pentru că cele două caută urmele acelui paria al familiei, unchiul Patrick, care conduce o afacere dubioasă (ca toate personajele cărții de altfel, care inventează tot felul de afaceri ciudate pentru a trăi) şi de la care ele speră să afle detalii despre mama lui, care este şi bunica Amaliei. În felul acesta, cele două părți ale familiei, aflate schizoid de o parte şi de alta a oceanului, îşi vor putea relua poveştile fantasmagorice şi merge mai departe. E o logică absconsă într-adevăr, dar cred că integrarea în lumea nouă e abia într-un final economică. În primul rând, ea se joacă pe coordonate spațiale şi temporale, în luptă cu marginalitatea. Şi, ca o adevărată nomadă ce este, Amalia exprimă extrem de poetic această condiție a marginalității, prin întâlnirile pe care le are şi prin vulnerabilitatea pe care o afişează. Noul continent reprezintă, printre altele, cadoul acestei condiții a vulnerabilității.

\section{Chipul personajului tău poartă lumina maternității într-o lume masculină indecisă şi dezertoare.}

Să ştii că eu admir în egală măsură această lume masculină indecisă şi dezertoare. Nu vreau nicidecum să arunc o judecată morală asupra deciziei lui Armand de a se implica într-o comisie etică de decizie asupra existenței sau non-existenței uterului artificial. Nici asupra deciziei lui de a nu avea copii şi de a nu participa astfel la jocul biologic al naturii. E o decizie la fel de legitimă ca şi cea a Amaliei de a-şi asuma rolul de mamă singură. Romanul se termină tocmai cu iminenta venire a fiului ei, cu aşteptarea lui pe malul fluviului Saint-Laurent şi cu intuiția femeii că acest fiu nu va cunoaşte niciodată setea. Nu e aşadar o teză pe care vreau s-o impun. Atât femeile, cât şi bărbații au dreptul la aventură, la non-responsabilitate. Iar în momentul în care ei devin blânzi, „non-periculoşi”, iar deciziile lor nu amenință în niciun fel situații de fapt, se poate spune că au ieşit în afara circuitului lumii. Se îndreaptă înspre altceva, desigur, poate mai stabil şi mai puțin haotic, însă lumea aceasta a călătoriei, a odiseei, a luat sfârşit. Las aşadar cititorului plăcerea de a alege soluția care i se pare cea mai 
potrivită pentru viitor. Lumea Amaliei, naturală, de asumare a maternității, chiar de una singură. Sau lumea profund artificială a lui Armand, de non-asumare, de reflecție perpetuă, o lume futuristă. Eu îmi exprim doar perplexitatea în fața acestei alternative.

Dintr-o dată, în cadrul narațiunii, apare figura misterioasă a bunicii Daria, ca o busolă care dă sens istoriei Amaliei. Daria joacă rolul unui fir conducător în istoria Amaliei. Ce ne poți spune despre ea?

Daria e o țărancă din Munții Apuseni care pleacă în America condusă de puterea premonițiilor ei, care face avere acolo în vremea prohibiției, care își lasă în spate copiii din prima căsătorie, promițându-le un viitor strălucit, care se îndrăgosteşte de Petru - complicele ei în afaceri necurate - în Canton, Ohio, căruia îi face un copil, pe Patrick, şi care într-o bună zi îşi pierde darurile premonitorii şi se hotărăşte, la fel de brusc cum a plecat, să se întoarcă în România. Numai că, la fel ca în basmul Tinerețe fără bătrânețe, o dată întoarsă acolo, începe să piardă totul, iar timpul se prăvăleşte peste ea. Îl pierde pe Petru, care se îndrăgosteşte de Agatha, mama Mariei, pierde dragostea copiilor ei. Izbucneşte războiul şi între cele două lumi se cască o prăpastie de netrecut. Daria e acel exemplu de Mutter Courage, al cărei farmec constă în furia supraviețuirii. E unul din personajele care au fost cele mai iubite de cititorii acestui roman, dacă e să mă iau după reacțiile pe care le-am avut.

Nu întâmplător Amalia porneşte împreună cu Maria, o rudă tot atât de visătoare ca şi ea, pe urmele unchiului pierdut undeva pe continentul american. Ocazie pentru naratoare de a face un jurnal de bord foarte detaliat al periplului ei american.

$\mathrm{Da}$, aici călătoria capătă valențele ei cele mai puternice. Amalia înregistrează gusturi, mirosuri, cozi de uragane, trecerea Katrinei, mlaştinile pline de crocodili, şerpii iridescenți din sud, casele înălțate pe piloni si personaje fugare care intersectează razant cele două stranii exploratoare. Jack Kerouac, dar şi Thelma şi Louise. Dacă Amalia aduce puțin cu Thelma, în vulnerabilitatea ei, Maria seamănă cu siguranță cu Louise, în camionul ei american şi în determinarea ei de fiică a noului continent. Am vrut aşadar să descriu şi prietenia profundă a celor două femei.

Cu toate acestea, în clipa în care Amalia - care urmează să nască - crede că povestea ei are un sens, ea este tulburată de elucubrațiile lui Armand, cercetător-vrăjitor în domeniul ectogenezei. Este, cred eu, mesajul cel mai puternic pe care-l transmiți în romanul tău, acela al permanenței iubirii şi al maternității, al corporalității, al conviețuirii bucuriei şi suferinței în luptă cu o lume postasfaltică, cum o numeşti tu, dezincarnată şi fără control. 
Acesta este unul din mesajele cărții mele. Într-adevăr, până la urmă cartea se termină cu iminența naşterii. Dar celălalt mesaj al cărții, poate la fel de puternic, este acela că această lume postasfaltică, în stranietatea ei, este, în acelaşi timp, o ocazie pentru experimentele cele mai interesante. Este o lume a viitorului, în tot ce are acest viitor mai provocator. Şi nu degeaba personajele care leagă cele două lumi sunt oameni cu o ascendență românească. Pentru că eu cred că unul dintre lucrurile cele mai tulburătoare care se pot spune despre acest popor, dincolo de propensiunea lui pentru umorul absurd, pentru băşcălie, este faptul că pune împreună nişte discrepanțe generaționale incredibile, arhaicul şi futuristul, fantasmagorii estetice de ultimă oră şi tradiționalismul extrem. În Cartografia lumii de dincolo, personajele trebuie să înghită cu repeziciune discrepanțe spațiale, temporale şi mentalitare uriaşe şi acest fapt le conferă farmec. Ele sunt entitățile perfecte pentru a fi supuse acestor experimente ale viitorului. Iar rezultatul - romanul ne lasă doar să-l întrezărim. 


\section{MARION LE ROY DAGEN}

\section{Dan BURCEA ${ }^{1}$}

Résumé : Marion Le Roy Dagen, née en Transylvanie en Roumanie, vit à Toulouse et travaille en tant que Chef de service dans le secteur socio-éducatif. Elle a cofondé en 2015 l'Association Française Orphelins de Roumanie (AFOR) pour accompagner dans leurs recherches des origines les orphelins adoptés en France mais nés en Roumanie. Elle a co-écrit avec l'écrivain Xavier Marie Bonnot L'enfant et le dictateur, paru chez Belfond en février 2018. C'est ce livre, en particulier, qui fait l'objet de l'interview proposée dans ce chapitre.

Mots-clés : Marion Le Roy Dagen ; L’enfant et le dictateur ; Interview.

Abstract: Marion Le Roy Dagen, born in Transylvania, lives in Toulouse and works as Head of Department in the socio-educational sector. In 2015, she co-founded the Association Française Orphelins de Romania (AFOR) to support adoptees born in Romania in their search for their origins. She co-wrote with writer Xavier Marie Bonnot, L'enfant et le dictateur, published by Belfond in February 2018. This book is the subject of the interview offered in this chapter.

Keywords: Marion Le Roy Dagen; L'enfant et le dictateur; Interview

\section{Introduction}

Marion Le Roy Dagen est née en Transylvanie en Roumanie. Elle vit à Toulouse et travaille en tant que Chef de service dans le secteur socio-éducatif. Elle a cofondé en 2015 l'Association Française Orphelins de Roumanie (AFOR) pour accompagner dans leurs recherches des origines les orphelins adoptés en France mais nés en Roumanie.

Elle a co-écrit avec l'écrivain Xavier Marie Bonnot L'enfant et le dictateur, paru chez Belfond en février 2018.

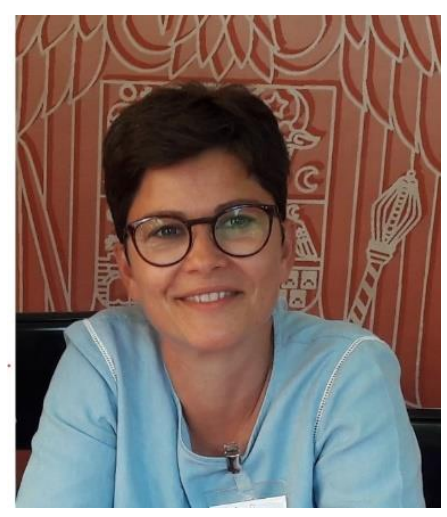

${ }^{1}$ Critique littéraire français d'origine roumaine,dmburcea@gmail.com 
Son premier ouvrage vient d'être publié en Roumanie à la maison d'édition Humanitas : « Copilul și dictatorul ».

Xavier-Marie Bonnot vit à Paris. Écrivain et réalisateur de films documentaires, il est notamment l'auteur de La Dame de pierre (Belfond, 2015, prix du Meilleur roman francophone au festival de Cognac ; Pocket, 2016), de La Vallée des ombres (Belfond, 2016), de Le Dernier Violon de Menuhin (Belfond, 2017), de L'Enfant et le Dictateur, avec Marion Le Roy Dagen (Belfond, 2018) et du Tombeau d'Apollinaire (Belfond, 2018, prix du Roman historique).

\section{Interview. Marion Le Roy Dagen : « Pour moi, ce livre est une force, une forme idéale d'exprimer ce que je ressens, un aboutissement » $^{2}$}

Xavier-Marie Bonnot, écrivain connu surtout pour ses polars, a su avec une grande délicatesse et sensibilité faire s'exprimer Marion Le Roy Dagen dans un livre bouleversant, L'enfant et le dictateur (Éditions Belfond) sur son parcours d'un orphelinat en Roumanie jusqu'à son arrivée en France, après son adoption. A l'âge de 18 ans, après la chute du régime communiste, elle part à la recherche de sa vraie histoire. Une quête d'identité pleine d'embûches mais aussi du bonheur de retrouver ces origines. Le livre sera traduit en roumain et paraîtra bientôt dans son pays d'origine.

\section{Que signifie l'horrible syntagme « enfants du diable » dont} vous parlez dans votre livre?

Une devise a guidé la politique nataliste de Ceausescu de 1965 à 1989 : «Un pays fort est un pays peuplé ». Les enfants du diable sont issus symboliquement de la dictature de ce couple diabolique. Leur politique pro-nataliste a créé une génération d'enfants non désirés. Ainsi, des dizaines de milliers d'enfants ont été placés en institution, soit parce qu'ils sont nés hors mariage, soit de parents divorcés ou de familles décomposées, soit de familles en grande détresse ou trop pauvres pour nourrir une bouche de plus. Beaucoup préféraient se tourner vers l'État pour lui confier leur enfant le temps de l'amélioration de leur situation. La plupart de

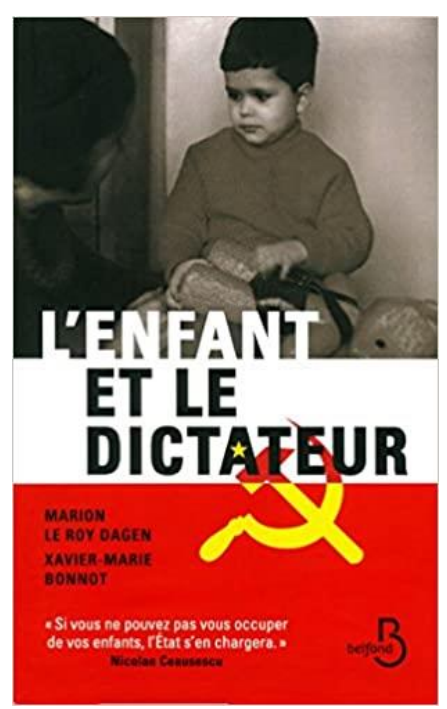

2 Interview réalisée par Dan Burcea.

Marion Le Roy Dagen, L'enfant et le dictateur, Éditions Belfond, févr. 2018, 224 p. Liens utiles : http://orphelinsderoumanie.org/; Une version en roumain de cette interview a été publiée dans l'hebdomadaire Observator cultural de Bucarest. 
ces enfants étaient " des orphelins sociaux », il y avait donc très peu d'abandon. Ce que nous mettons en avant dans le livre avec Xavier-Marie c'est que Ceausescu a imposé des conditions de vie austères à sa population par le rationnement de la nourriture et de l'énergie. Et ces conditions étaient les mêmes dans les institutions qui accueillaient les enfants et qui étaient très souvent surpeuplées. Aujourd'hui, beaucoup d'adultes qui ont survécu à ces multiples violences sont dans une démarche de demande de réparations auprès de l'État roumain.

\section{Quand avez-vous pris connaissance de leur triste sort ?}

J'ai commencé à m'y intéresser dès l'âge de mes 13 ans. J'ai vu des reportages sur ces enfants et des photos faites par des photographes reconnus comme Elisabeth Blanchet qui a travaillé pendant près de 20 ans avec des enfants placés en institution à Popricani, au nord de la Roumanie. J'ai ressenti de la douleur pour "mes camarades ». Et même si le mot « camarade » n'était peut-être pas le plus approprié, j'ai compris que nous avions tous vécu la même expérience, le placement, les souffrances, la négligence humaine, nous étions tous comme des enfants fantômes, issus d'un système politique très difficile.

Pourquoi vouloir écrire un livre, « mettre tout sur papier »?

L'idée d'écrire un livre m'est venue en 2011. C'est à partir de ce moment que j'ai dû me résoudre à mettre sur papier ma souffrance, ma colère, mes humiliations. Dans un premier temps, j'ai beaucoup écrit et cela m'a tellement fait de bien que j'ai pris la décision de donner à ce que j'avais écrit une forme plus unitaire, tout en éveillant des souvenirs enfuis dans ma mémoire et qui apparaissaient sous forme d'odeurs et de beaucoup de choses du niveau sensoriel. Il m'a fallu sept ans pour tout écrire. Entre temps, j'avais réalisé le film documentaire L'enfant du diable avec la photographe Elisabeth Blanchet. Mon livre est né de ce désir de boucler la boucle et de la volonté d'exprimer d'une autre façon beaucoup plus de choses sur les personnes concernées par mon adoption, sur mes parents adoptifs mais aussi sur mes parents biologiques, avec leur accord, bien entendu. Pour moi, ce livre est une force, une forme idéale d'exprimer ce que je ressens, un aboutissement.

\section{Comment avez-vous écrit ce livre, aviez-vous un plan, une méthode?}

Non, pas du tout, au début j'ai commencé à écrire suivant le fil des souvenirs. Ensuite j'ai suivi l'ordre chronologique des événements. Le déclic a eu lieu lorsque j'ai rencontré Ana, ma mère biologique. C'était tellement fort que j'avais peur de l'exprimer. Ce qui a été le plus difficile c'est qu'après avoir écrit environ 80 pages j'avais besoin d'un regard extérieur sans que pour autant les gens me plaignent, même si pour moi c'était douloureux. C'est pour cette raison que j'ai parlé du projet à XavierMarie Bonnot qui, à ma grande joie, a accepté tout de suite. Cette co- 
écriture a été douloureuse mais très bénéfique. Cela a réveillé des émotions intenses et enfouies, comme des pleurs, des peurs, des angoisses, des joies bien sûr qui m'ont amenée à de longues insomnies. Je me suis longuement interdit d'exprimer mes blessures pour me protéger. Xavier-Marie a su gagner ma confiance grâce à sa bienveillance, à son respect, à sa patience et à sa sensibilité.

\section{Revenons au Noël 1989. Que se passe-t-il à ce moment ?}

Je me souviens parfaitement de ce Noël 1989. J'avais 13 ans à l'époque et je vivais la période de ma pré-adolescence où je n'étais pas trop bien dans mon corps et où je commençais à me poser des questions sur mon adoption, sur mes origines, sur la Roumanie, sachant que j'avais peu d'informations sur ce pays. Le sujet était tabou avec mes parents, il fallait donc que je fasse avec. Mais lorsque je suis tombée sur ces images, je me suis dit, c'est mon pays, mais qu'est-ce qui se passe ? Pour moi, c'était un bouleversement et je n'arrivais pas à croire qu'il s'agissait d'une révolution, avec tous ces visages et cette atmosphère glaciale et ensuite avec cette mise à mort du couple Ceausescu. Cela m'a énormément marquée d'autant plus que je n'avais pas à qui l'exprimer. J'ai gardé tout ça au plus profond de moi, tout en m'interrogeant sur ce que je pouvais faire de ce que je découvrais. Cela faisait aussi partie de mon histoire, il s'agissait de mon pays et je cherchais des éléments liés à mon abandon et à mon placement en institution.

J'ai pensé qu'avec le temps j'arriverai un jour à partir directement en Roumanie.

\section{Avant de partir en Roumanie, aviez-vous des informations concernant le village de Teius, de Nicolae et d'Ana, vos géniteurs?}

Les seules informations que j'avais concernaient mon nom de naissance, le nom de ma mère biologique, mon lieu de naissance, Aïud. Ensuite, mes parents adoptifs m'avaient dit que ma mère biologique était décédée dans un accident de voiture et que j'avais un père inconnu. Ils avaient reçu une lettre officielle où la directrice roumaine leur avait donné ces informations. Lorsque je suis partie pour la première fois en Roumanie, ce n'était pas pour rechercher mes parents. J'étais attirée par mon pays d'origine, par mon sang. Je fantasmais sur la Roumanie avec l'enthousiasme de la jeunesse qui voyait en elle un pays merveilleux, comme la France. Lorsque je suis arrivée à destination le choc a été incroyable.

\section{Étiez-vous seule?}

Non. J'étais partie avec une association du sud de la France, avec toute une équipe d'adultes. Je suis allée à Alba Iulia pour visiter le leagăn, la pouponnière, où j'avais été placée. Nous sommes arrivés à l'improviste et j'ai revu des membres du personnel qui s'étaient occupés de moi. Les choses avaient changé, je ne ressentais plus cette sensation d'enfermement, les locaux étaient décorés. Ce qui m'a également marquée 
c'est que les enfants jouaient dans la cour, ce qui pour moi avait été une chose inconcevable à l'époque.

Le personnel a appelé la directrice, le docteur Mitea, qui est arrivée très rapidement. Je lui ai reposé des questions concernant ma mère biologique. Elle m'a redit qu'elle était morte. Raymond, un compagnon de voyage, m'a dit que j'avais maintenant toutes les réponses concernant ce sujet. Je lui ai répondu que je ne croyais pas, quelque chose au fond de moi me disait que ce n'étais pas vrai. J'avais besoin d'une preuve, d'une note de décès, d'une tombe, avec tous les éléments capables de me prouver cette mauvaise nouvelle.

\section{Quels souvenirs gardez-vous du leagăn de Alba Iulia ?}

J'ai des souvenirs de visages d'enfants, de mes compagnons, et surtout des souvenirs d'odeurs, de bruits, de cris. J'ai été plus marquée par ces choses que par le manque d'affection, par exemple. J'ai été dans cet établissement jusqu'à l'âge de cinq ans, alors que normalement j'aurais dû le quitter à l'âge de trois ans. La directrice m'a gardée dans l'espoir que je serais adoptée plus rapidement mais aussi pour me protéger des violences qui étaient courantes autour de nous. Finalement, j'ai été transféré dans une casa de copii, une maison pour enfants, à Bucarest, un établissement pour des enfants plus grands. Nous étions plus nombreux, il y avait des grillages, de nombreux enfants plus grands avec les têtes rasées, toutes des filles, nous avions les mêmes uniformes, beaucoup étaient au bord de la dépression et même de la folie.

Quels souvenirs gardez-vous de votre premier contact avec vos parents adoptifs?

J'avais vu mes parents adoptifs à l'âge de quatre ans. Eux, comme moi, nous nous attendions que les formalités durent peu de temps, alors qu'elles ont duré presque 2 ans. C'était insupportable pour eux comme pour moi. Une fois l'accord de mon adoption signé par Nicolae Ceausescu, mes parents ont pu venir me chercher à Bucarest.

Votre première rencontre avec Robert, votre père ?

Évoquer la personne de mon père me touche beaucoup car il est décédé il y cinq ans et je garde de lui des souvenirs inoubliables. Notre première rencontre a été comme un coup de foudre mutuel, un moment trop court mais fabuleux. J'étais d'autant plus fascinée par lui parce que dans le milieu où je vivais je ne voyais que des femmes, il n'y avait pratiquement pas d'hommes. En même temps, on peut parler d'une chance, parce qu'il y a des rencontres où il ne se passe rien.

Vous arrivez finalement en France. Vous avez la volonté de forcer le destin, d'avancer. D'où venait cette force ?

Je crois que j'ai hérité cela d'Ana, ma mère biologique, c'est donc génétique. Mais je pense que c'est aussi une forme de résilience. J'avais besoin de comprendre et de me dire qu'on est maître de sa vie et de ses 
décisions. Je me suis dit que je devais aller chercher mes vérités. C'était difficile, surtout que je n'avais personne à qui exprimer ces sentiments, par peur d'être abandonnée. C'était une époque où l'on ne parlait pas de tout cela. Je ne regrette rien de tous mes voyages en Roumanie et je remercie la vie de m'avoir permis tout ça.

Vous avez fondé une association pour les adoptés roumains en France. Pourriez-vous nous en dire plus?

Oui, il s'agit de l'Association française des orphelins de Roumanie (AFOR), créée avec mon amie, Laura Giraud. Laura avait besoin d'un espace de parole. Elle avait créé un blog et elle s'est rendue ainsi compte que beaucoup de personnes souhaitaient raconter leur expérience. Je suis allée à sa rencontre et nous avons décidé de mettre les bases de cette association. Nous avons utilisé le mot « orphelin » pour évoquer la tripartie de l'adoption, l'enfant, la famille biologique et la famille adoptive. Le mot n'avait pas pour nous un sens de perte, mais de privation. Nous avons eu beaucoup de demandes en France, en Belgique, en Espagne, en Grande-Bretagne, au Québec et en Roumanie. Nous avons fait appel à des spécialistes, à des thérapeutes, à la fois pour les enfants et pour les familles biologiques. Aujourd'hui L'AFOR fait une pause.

\section{Comment répondez-vous aux demandes de formalités administratives?}

Nous travaillons avec les autorités roumaines avec qui nous avons mis en place tout un protocole administratif qui permet d'entreprendre des recherches concernant divers documents comme, par exemple, actes de naissance, jugements d'adoption, etc. Le dispositif mis en place en 2004 en Roumanie est très performant.

\section{Comment cela se passe-t-il sur le terrain?}

Dès que l'administration reçoit les dossiers, les services de l'État démarrent les recherches pour savoir si les parents biologiques sont encore vivants et s'ils peuvent être localisés. Les services sociaux départementaux rentrent ensuite en contact avec ceux-ci, tout en préservant le secret de chaque famille. Il arrive que des enfants soient issus d'une relation secrète ou de violence sexuelle, et tout cela doit être traité avec attention. Si la famille accepte de rencontrer l'enfant, le protocole se met en route, mais s'ils refusent tout s'arrête à ce stade. Les autorités respectent l'avis des familles, tout en leur donnant la possibilité de revenir sur leurs décisions au cas où ils changeraient d'avis. Nous réfléchissons à la manière dont sont pris ces contacts, ce qui nous permet de répondre aux questions qui surgissent ultérieurement. Lorsque nous recevons les réponses de la part des autorités roumaines, nous nous chargeons de communiquer les réponses et les documents officiels.

Y a-t-il des dangers si l'on recourt aux moyens non-officiels comme les réseaux sociaux, par exemple? 
Oui. Notre travail est d'autant plus important qu'actuellement, il y a une explosion de recherches des origines via les réseaux sociaux. Nous tirons la sonnette d'alarme parce qu'il y a un marché où des gens se font passer pour des détectives privés, qui demandent des sommes d'argent, mais surtout des documents et des données personnelles avec lesquels ils peuvent faire du trafic. Lorsqu'ils arrivent à rentrer en contact avec leurs familles biologiques, souvent tout se passe très mal. Échanger quelques mots dans une réalité virtuelle ne suffit pas à les préparer à un tel événement. Nous les conseillons d'éviter le plus possible les réseaux sociaux et de faire appel aux organismes spécialisés.

La vérité obtenue par ces recherches est-elle facile à porter ?

C'est un aspect essentiel sur lequel j'insiste : que fait-on de cette vérité, quelle qu'elle soit ? C'est ce qui est le plus difficile. Ce besoin implique l'acceptation ou le renoncement à cette vérité. C'est ce que j'essaie d'expliquer dans notre livre, il s'agit d'un long cheminement qu'il faut accepter surtout de la part de l'adopté mais aussi pour la famille biologique. Dans le cadre de mon travail social, j'ai rencontré des enfants adoptés au bord du suicide, incapables de porter une vérité trop douloureuse. Mon expérience m'a prouvé que, face à cette situation très complexe, les adoptés sont démunis face à la complexité législative.

Les journalistes étrangers ont parlé souvent des orphelinats roumains. Quel est votre avis en écho à beaucoup de leurs réactions?

Je me suis longuement entretenue avec des journalistes à ce propos. Tout le monde est d'accord pour dire que les Roumains eux-mêmes ne connaissaient pas l'existence et la réalité de ces établissements. Dans mes travaux de recherches avec des spécialistes de l'Université de Iasi, j'ai appris que des collègues français les ont interpellés au sujet d'une responsabilité générale vis-à-vis de ces orphelinats. Personnellement, je n'accepte pas ce type de critique, s'il y a une responsabilité, celle-ci doit être mise sur le dos du régime totalitaire et non pas du celui de tout un peuple tenu dans l'ignorance de cette tragédie. Lorsque je raconte avec Xavier-Marie dans ce livre mon histoire, l'objectif n'est pas de dénoncer une réalité, mais de raconter mon histoire afin que de telles choses ne se reproduisent plus.

\section{Votre livre va être traduit et publié bientôt en Roumanie. Comment voyez-vous cet événement?}

C'est avec grande joie que je souhaite rencontrer le public roumain et échanger avec eux. Cela me permettra aussi de continuer certains échanges sur la quête d'identité que j'ai pu avoir avec des gens lors de mes voyages en Roumanie. Ce sont toutes ces choses enrichissantes que j'espère leur transmettre à l'occasion de la parution de mon livre en roumain. 


\section{FLORENTINA POSTARU}

\section{Dan BURCEA ${ }^{1}$}

Résumé : Écrivaine franco-roumaine, originaire de Tulcea, Roumanie, Florentina Postaru, passionnée de littérature française, décide de s'auto-exiler en Bretagne. Elle collabore aujourd'hui à Lorient à une radio associative. En novembre 2019 Florentina publie son premier livre, Heureux qui comme mon aspirateur, a fait un beau voyage, aux Éditions Bayard, le récit de son enfance jusqu'à l'arrivée en France, illustré par Serge Bloch. Elle intervient souvent dans les établissements scolaires pour raconter la dictature roumaine et faire découvrir son pays, loin des clichés habituels. Linterview explore l'usage de l'humour et la mémoire du régime communiste de l'écrivaine.

Mots-clés : Florentina Postaru ; Régime communiste ; Interview.

Abstract: Franco-Romanian writer from Tulcea, Romania, Florentina Postaru, fond of French literature, decides to self-exile in Brittany. She now works in Lorient for an associative radio station. In November 2019 Florentina published her first book, Heureux qui comme mon aspirateur, a fait un beau voyage, with Éditions Bayard, the story of her childhood until arriving in France, illustrated by Serge Bloch. She often intervenes in schools to tell the story of the Romanian dictatorship and to makes others discover her country, far from the usual clichés. The interview explores the usage of humor and the communist regime memory of the writer.

Keywords: Florentina Postaru; Communist Regime; Interview

\section{Introduction}

Florentina Postaru est une écrivaine franco-roumaine, née en 1977 à Tulcea en Roumanie. Dans les années 1990, passionnée de littérature française, elle part étudier à Bucarest. À 37 ans, elle décide de s'auto-exiler en Bretagne. Elle collabore aujourd'hui à Lorient à une radio associative. En novembre 2019 Florentina publie son

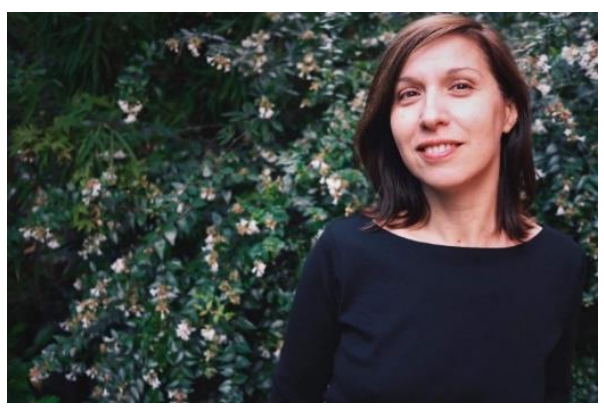

${ }^{1}$ Critique littéraire français d'origine roumaine,dmburcea@gmail.com 
premier livre, Heureux qui comme mon aspirateur, a fait un beau voyage, aux Éditions Bayard, le récit de son enfance jusqu'à l'arrivée en France, illustré par Serge Bloch. Elle intervient souvent dans les établissements scolaires pour raconter la dictature roumaine et faire découvrir son pays, loin des clichés habituels.

2. Interview. Florentina Postaru : «L'humour a été un médicament pendant ce régime maladif. Il montre bien l'absurde de cette période tragique de la Roumanie »²

Florentina Postaru publie Heureux qui, comme mon aspirateur..., un livre dont seuls les propos faisant référence à l'humour qui accompagne le texte arrive à adoucir l'avertissement contenu dans le sous-titre "Grandir dans la dictature roumaine ». À une distance de 30 ans de la chute du régime, la génération des enfants de l'époque qui ont aujourd'hui la quarantaine se retrouve à une mi-distance lui permettant un regard plus détaché, voire apaisé devant ces événements sanglants. Car, sinon, comment interpréter la « folle aventure » de ce livre et comment lire ces textes écrits comme des partitions musicales ? La romancière roumaine semble avoir trouvé la clé lui permettant de naviguer à travers l'histoire, tout en évitant que cette légèreté supposée n'insulte la mémoire contenue dans son livre. Son secret ? Seules l'innocence du regard enfantin et la volonté d'exorciser l'impossible attente d'un monde meilleur sont capables de gagner à la fin un tel pari.

Ai-je raison de dire que seul un certain détachement permet à l'humour et au sens de la dérision de gagner du terrain devant la mémoire et le caractère répressif du régime ? Le considérez-vous comme un privilège générationnel ? Sinon, comment expliquer votre démarche littéraire dans l'écriture de ce livre?

Oui, vous avez raison, mais aussi, l'humour a été un médicament pendant ce régime maladif. L'humour montre bien l'absurde de cette période tragique de la Roumanie et il est lié à notre peuple : " mieux vaut rire que pleurer », cite toujours mon père. J'ai commencé à écrire mon enfance à

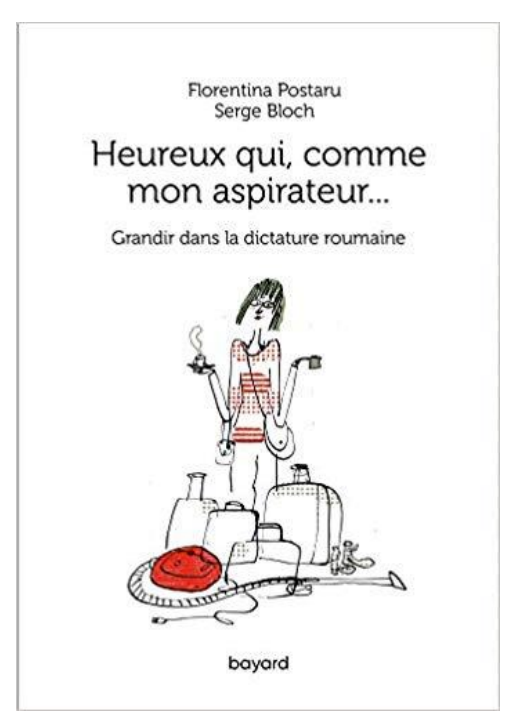

2 Interview réalisée par Dan Burcea

Florentina Postaru, Heureux qui, comme mon aspirateur..., Éditions Bayard Culture, 2019, $280 \mathrm{p}$. 
la demande d'une amie, professeur, pour aller dans un collège en Bretagne et raconter mon histoire aux enfants. Loin de ma famille, de mes amis, de Roumanie, j'ai déroulé mes souvenirs avec beaucoup d'intensité, j'ai ouvert des tiroirs fermés depuis longtemps et ma mémoire m'a tout remis à disposition. Ma mère était surprise de tous les détails qui me revenaient, elle m'a dit un jour que j’avais une mémoire presque dangereuse.

Pourquoi avoir opté pour la narration à la première personne ? Craigniez-vous un certain éloignement et une perte d'authenticité en confiant votre histoire à une « narratrice » autre que Floricel ?

Raconter à la première personne c'est écrire avec le cœur, tout assumer, ne pas faire de concessions : reconnaître des faiblesses, des torts, jouer avec l'autodérision. Le lecteur m'accompagne au long de ma vie, presque 40 ans, et suit Floricel à la maternelle et à la maison, Flori au collège, Floarea au village de mes grands-parents et plus tard Florentina au travail. C'était tellement personnel que je n'arrivais pas à me détacher $\mathrm{du}$ « Je » et de parler de moi à la $3^{\mathrm{e}}$ personne.

Dès les premières pages, on apprend que votre personnage porte en lui ce que vous appelez « les balbutiements d'une révolutionnaire ». Comment comprendre cette douce preuve d'autodérision ? Les Roumains sont-ils tous tels que votre héroïne?

Je raconte dans mon livre une histoire : petite, j'adorais assister mon père dans la cuisine. Un jour, il m'a dit de taper la polenta chaude avec la main. Je l'ai fait vite sans hésitation et bien sûr me suis brûlée. Mon père m'a alors expliqué qu'il ne fallait pas toujours obéir sans réfléchir. Mes parents ont essayé tout au long de nos vies d'enfant de nous faire réfléchir avant d'exécuter un ordre. Ma mère nous a toujours stimulé à répondre, même quand elle nous grondait. Je ne peux pas généraliser pour tous les Roumains, je pense que la révolution roumaine a donné une impulsion de courage aux gens pour s'exprimer, pour dire « ça suffit ».

Entre la discipline, les uniformes tristes, le froid et les punitions en classe, que retenez-vous de votre scolarité ? Vous parlez même d'une dictature aux multiples visages, où chacun est porteur d'une autorité débordante.

J'avais souvent ce sentiment, chaque personne aurait pu être un dictateur : le prof principal en classe, l'entraîneur de handball, ma sœur avec moi. Une forme d'autorité envers les plus faibles existait à tous les niveaux. Même la vendeuse de l'épicerie avec son pouvoir exerçait cette forme d'oppression, la dame qui vendait les billets dans le bus... partout on observait des comportements de potentiel dictateur. Ma scolarité pendant les années '8o a été dure, mais j'ai eu la chance de rencontrer aussi de vrais 
pédagogues qui ont ouvert mon envie d'apprendre des langues étrangères, de voyager, de lire, de découvrir des choses intéressantes.

Inoubliables sont les vacances d'été chez vos grandsparents que vous faites revivre avec un inaltérable amour.

Les vacances, nous les passions à Sabangia, un village situé à $35 \mathrm{~km}$ de Tulcea. Notre bande de quatre cousins remplissait d'amour et de bruit la cour et la maison de mes grands-parents. Pendant l'été, trois mois sans chaussures à jouer dehors, aider dans les jardins, chanter dans la balançoire, courir : c'était la liberté pour nous. C'était le moment le plus attendu de l'année. Puis, pendant l'hiver, le Noël, couronné par l'assassinat d'un ou plusieurs Ghita (le chapitre-hommage pour tous les cochons sacrifiés pour Noël). J'ai écrit un chapitre-portrait de ma grandmère, Fiofana. Quand je l'ai lu à ma famille, nous avons eu les larmes aux yeux. L'amour pour elle restera en nous pour toujours.

\section{Pourriez-vous nous parler aussi de vos parents à qui vous dédiez votre livre ?}

Mes parents sont des gens simples qui ont tout donné pour ma sœur et moi. Ma mère travaillait à l'usine d'aluminium et mon père en métallurgie. Il est passionné par l'histoire et par la littérature française. Mon père nous a donné l'envie d'être curieuses, de chercher, de connaître, de comprendre. Ma mère nous achetait des livres, elle adorait l'écrivain Marin Preda. Ils ont toujours voulu nous offrir ce qu'ils n'ont pas eu : l'accès à l'école et aux études.

Je pense toujours qu'ils ont coloré avec leurs moyens mon enfance pendant cette période grise de notre histoire : mon père avec son humour et ses blagues, ma mère avec son amour et sa loyauté.

Vous affirmez que de toutes les privations du régime, les queues devant les magasins d'alimentation sont restées pour vous un des plus tristes souvenirs. De quoi s'agit-il ?

Sauf le froid, le noir et les privations, la queue représente un souvenir très fort. Faire la queue pour tout : le lait, l'huile, le pain, la bouteille de gaz, place au cinéma, librairies... pour tout ! C'était une forme d'humiliation de ce régime malade qui nous rendait impuissants. J'ai réalisé tard tout cela. Enfant, je préférais être dehors avec les amis pour faire la queue et jouer en même temps. Ramener les griffes de poulet était une récompense après des heures et des heures d'attente. Partir en même temps que mes parents à six heures du matin pour faire la queue afin de ramener du lait faisait partie de notre quotidien. C'était le rituel de notre existence.

Quel âge aviez-vous au moment de la Révolution de décembre en Roumanie ? Quels sont les souvenirs que vous évoquez dans votre livre ?

En décembre 1989 j'avais presque 13 ans. Je sens beaucoup d'émotion chaque fois que j'en parle. J'ai senti la peur pour la première 
fois, la vraie peur qui paralyse. Je me trouvais à Mangalia avec toute l'équipe féminine de handball du club sportif de Tulcea. Les premiers jours nous sentions nos entraîneurs agités et moins investis par leur tâche. Le 22 décembre pendant le moment du déjeuner ils nous ont annoncé la nouvelle : Ceausescu était parti, c'était la révolution. La question de Sabina : « on aura des bananes maintenant ? » résonne encore dans ma tête, 30 ans après. Ensuite, la nuit de 22 décembre, ils nous ont réveillés à 2 heures du matin et nous ont amenées sur un petit stade, dans le froid, dans le noir, sur le fond sonore des canons... j'ai vécu cette peur, la peur d'entendre de si près des armes. En rentrant à Tulcea, le jour de Noël, chez nous, il y avait une atmosphère différente des autres années, une joie pas assumée, un mélange entre bonheur et peur du futur.

Une vraie liberté annonce son arrivée dans le pays. Que vous dit-elle cette liberté à ce moment de votre vie ?

De nouveaux mots sont entrés dans notre vocabulaire, utilisés abondamment : victoire, démocratie mais surtout CHOISIR. Choisir comment s'habiller pour aller à l'école, choisir la chaîne télé, la musique. Nous étions la génération qui apprenait à faire des choix. C'était extraordinaire. Découvrir la musique, aller en boîte, avoir des jeans, commencer à ressembler aux occidentaux, regarder TV5, écouter sans arrêt cette belle langue et enfin connaitre l'abondance et le confort : finies les queues, finies les coupures électriques, du chauffage tout le temps et même du chocolat!

D'où vient le premier contact avec la langue et la littérature françaises ? Qu'a représenté pour vous l'ouverture vers ce nouvel horizon ? Et plus tard pour votre activité professionnelle?

Mon père est passionné par la littérature française. Enfants, nous avons lu ensemble, avec mes cousins, les aventures des trois mousquetaires, les voyages de Jules Verne et plus tard dans la bibliothèque de la famille j'ai découvert Stendhal et Flaubert. Au lycée j'ai étudié en principal la langue et la littérature française et puis à Bucarest j'ai continué dans cette voie. Plus tard, une entreprise française cherchait des jeunes qui parlaient français, et c'est ainsi que j'ai commencé à travailler chez Carrefour et je suis venue en France pour des formations, je découvrais ce pays magnifique.

Comment avez-vous décidé de quitter la Roumanie pour venir en France ? Et comment vivez-vous entre ces deux pays ?

J'ai pris la décision vite, un matin de novembre 2013, j'avais 37 ans. C'était un rêve de jeunesse, vivre ailleurs, voyager. La situation dans mon pays m'a poussé à partir et à devenir une étrangère. Je suis partie seule, pour reprendre tout à zéro. Il m'a fallu une bonne dose de courage mais aussi de folie. L'intégration n'a pas été facile mais petit à petit j'ai réussi à 
construire ma nouvelle vie ici. Mes proches me manquent beaucoup, parler le roumain aussi. Je rentre au pays tous les ans, au moins une fois, généralement pour Noël.

\section{Parlez-nous de votre collaboration avec Serge Bloch qui} illustre de ses dessins votre livre.

J'ai envoyé les premiers textes à Serge et il a voulu me rencontrer. Je connaissais un peu son travail. J'avais acheté un de ses livres, très fort Eux, c'est Nous, une collaboration avec Daniel Pennac. Serge m'a dit que, si je le souhaitais, il était d'accord pour illustrer mon enfance. Quelques mois plus tard, j'ai reçu les premiers dessins. Il avait tout compris, il avait capté tout ce que je raconte, j'avais l'impression qu'il avait été avec moi, à Tulcea, dans le petit appartement de ma famille, à Sabangia, chez mes grands-parents ou sur la terrasse de " La Motoare » à Bucarest pendant les années 2000. 


\title{
5. IRINA TEODORESCU
}

\section{Dan BURCEA'}

Résumé : Irina Teodorescu est une romancière d'origine roumaine et d'expression française. Elle quitte la Roumanie pour venir à Paris en 1998, où elle exerce le métier de graphiste et crée une petite agence de communication avec deux collaborateurs. Son premier roman, La Malédiction du bandit moustachu, est remarqué par Le Figaro littéraire, qui a fait d'Irina Teodorescu l'un de ses dix nouveaux visages de la rentrée littéraire 2014. Il a été publié en roumain chez Polirom. Son dernier roman, $\mathrm{Ni}$ Poète ni animal, fait partie des six coups de cœur de la rentrée littéraire 2019 de l'édition parisienne du magazine Vogue. Le chapitre présente des interviews sur différents sujets ayant trait aux romans de cette écrivaine.

Mots-clés : Irina Teodorescu ; Romancière ; Interview.

\begin{abstract}
Irina Teodorescu is a Romanian-born, French-speaking novelist. She left Romania to come to Paris in 1998 where she worked as a graphic designer and created a small communication agency with two collaborators. Her first novel, La Malédiction du bandit moustachu, was praised by Le Figaro littéraire, and included as one of the ten new titles proposed for the 2014 literary season. It was published in Romanian by Polirom. Her latest novel, Ni Poète ni animal, is one of the six favorites for the 2019 literary season of the Paris edition of Vogue magazine. The chapter features interviews on various subjects and the writer's novels.
\end{abstract}

Keywords: Irina Teodorescu; Novelist; Interview.

\section{Introduction}

Irina Teodorescu est une romancière d'origine roumaine, d'expression française. Elle quitte la Roumanie pour venir à Paris en 1998 où elle exerce le métier de graphiste et crée une petite agence de communication avec deux collaborateurs. Son premier roman, $L a$ Malédiction du bandit moustachu, est remarqué par Le Figaro littéraire, qui a fait d'Irina Teodorescu l'un de ses dix nouveaux visages de la rentrée littéraire 2014. Il a été publié en roumain chez Polirom. Son dernier roman, Ni Poète ni animal, fait partie des six coups de cœur de la rentrée

${ }^{1}$ Critique littéraire français d'origine roumaine, dmburcea@gmail.com 
littéraire 2019 de l'édition parisienne du magazine Vogue. Pour Les Inrockuptibles « Il est des images qui longtemps resteront dans les mémoires des lecteurs d'Irina Teodorescu ». Pour Le Monde des Livres, l'écriture emploie un "style bigarré, fin et drôle, remarquablement enlevé » et "Irina Teodorescu fait, avec Ni poète ni animal, un éloge de l'étrange, dont elle affirme avec subtilité mais force la puissance à la fois littéraire et politique. Superbe ».

2014 : prix SGDL Dubreuil du premier roman pour La Malédiction du bandit moustachu

2014 : prix ADELF Europe pour $L a$ Malédiction du bandit moustachu

2017 : prix Récit de l'Ailleurs (Saint-Pierre-

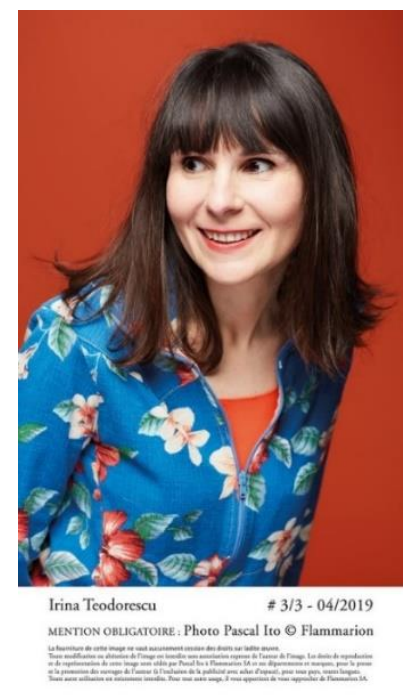
et-Miquelon) pour Les Étrangères

2018 : finaliste du prix Ouest-France Étonnants Voyageurs pour Celui qui comptait être heureux longtemps

\section{Interview. IRINA TEODORESCU : « Il y a tellement de moi, il y en a autant que de points sur une ligne tracée entre Bucarest et Paris »}

Entre Irina Teodorescu et ses lecteurs il y a d'abord la fabuleuse histoire de La malédiction du bandit moustachu (Gaïa, 2014), roman traduit en roumain chez Polirom (2016, Prix André Dubreuil -SGDL du premier roman ; Prix Europe 2014 de l'Association des Écrivains de Langue Française (ADELF) et ensuite celle un brin autobiographique décrite dans Les étrangères (Gaïa, 2015, Prix littéraire Récits de l'Ailleurs, attribué par un jury de lycéens de Saint-Pierre et Miquelon). La critique n'est pas en reste, la carrière de la jeune franco-roumaine s'ouvre généreusement devant elle, à la mesure de son talent. Deux raisons pour demander à l'intéressée comment elle vit cette belle aventure littéraire et quel sens elle donne au titre d'écrivain roumain de langue française.

Cette personne, l'écrivaine roumaine d'expression française, n'est pas moi. Moi je suis cette fille dans ce train, assise n'importe comment, que les gens regardent de travers parce qu'elle occupe quatre places tout en faisant semblant de dormir. Je suis la même que j'étais en $\mathrm{CP}$, en $\mathrm{CM} 2$, en troisième, en terminale etc. Je prends des cours de couture. Je rêve de pouvoir me fabriquer toute seule une robe dans laquelle ma silhouette soit parfaite. Je rêve que je danse très bien. Je vais courir une ou deux fois par semaine. J'ai des amis. J'ai un amoureux, des enfants, un chat. J'ai des cahiers dans lesquels j'écris. Je n'ai pas de pensée politique 
particulièrement construite. Je n'ai pas assez d'ambition. Puis mes livres sont là, des personnages, des histoires, des phrases, des mots, oui, ils sont là. Et moi, je marche dans une rue, je traverse un pont, une plage, une ville étrangère, une gare, je croise un regard et je me dis ce n'est rien, tout ceci n'est rien, c'est ma vie et puis la vie des autres, voilà tout. Peut-être que je refuse de prendre une responsabilité qui m'incombe. J'ai des lecteurs. J'écris un livre ou un article, on me lit. Je raconte une histoire, on m'écoute. On m'invite, on m'accueille, on me donne une place, puis une autre, on m'offre à manger, à boire, et puis on me demande. Pourquoi j'écris en français ? Pourquoi je suis roumaine? Pourquoi je suis française? Mais je me sens comment ? Et je suis chez moi où ? Et j'ai fait comment ? J'ai fait comme tout le monde. J'ai écrit un texte, j'ai envoyé un manuscrit par la poste. En lettre suivie, j'avais peur que ça se perde, j'ai encore le reçu, sept euros quelque chose. J'ai écrit un deuxième texte, je l'ai envoyé par e-mail cette fois-ci, puisque je connaissais maintenant mon éditrice. C'est difficile de répondre à cette question : que représente pour moi d'être moi ? Mais il y a tellement de moi, il y en a autant que de points sur une ligne tracée entre Bucarest et Paris. Une multitude de représentations de l'écrivaine roumaine d'expression française. Et chacune d'entre elles peut se diviser en plusieurs, une infinité d'Irina Teodorescu, celle qui a écrit, celle qui n'a pas encore écrit, celle qui y pense, celle qui n'y pense pas, celle qui est née, celle qui parle roumain, celle qui ne parle pas encore français, celle qui ne connait pas Barbara, celle qui se regarde dans un miroir déformant au jardin de l'Acclimatation alors qu'elle préférerait se balader parmi les cerisiers en fleur et manger une glace au chocolat.

\section{Irina Teodorescu : «La malédiction du bandit moustachu »}

En arrivant à l'âge de 19 ans en France depuis la Roumanie, Irina Teodorescu portait sans doute dans ses bagages une pile considérable de légendes dont le folklore des contrées danubiennes raffole, comme nous le savions déjà grâce à Panaït Istrati, l'ami des haïdouks et de Romain Rolland. Sauf qu'à une distance de deux générations de l'auteur de la Présentation des haïdouks, le regard de notre jeune romancière prend des allures plus désinvoltes, plus familières, délaissant les aspects punitifs, justiciers et patriotiques de ces « bandits d'honneur » d'autrefois au profit d'un espace narratif tourné d'une manière plus affirmée vers le fantastique et le loufoque. Son livre écrit en français est un exemple de ces mélanges de genres où l'on devine la trace - ne serait-ce que par la construction de sa narration en tableaux successifs - de la fraîcheur

${ }_{2}^{2}$ Irina Teodorescu, La Malédiction du bandit moustachu, Éditions Gaïa, septembre 2014, $154 \mathrm{p}$. 
sémillante dont fait usage la bande dessinée. Rien d'étonnant quand on sait qu'Irina Teodorescu est à la base graphiste et que l'écriture de son premier roman a eu comme point de départ l'exercice du dessin, comme elle l'affirme dans une récente interview.

C'est donc à cette construction faite d'aventures qui s'empilent d'une manière discursive et qui reposent sur le mythe fondateur de l'improbable malédiction d'un encore plus improbable personnage moustachu qu'incombe la tâche de créer la cohabitation entre le réel et l'imaginaire pour arriver à l'harmonie d'une histoire censée traverser le siècle jusqu'à la date salutaire de l'an

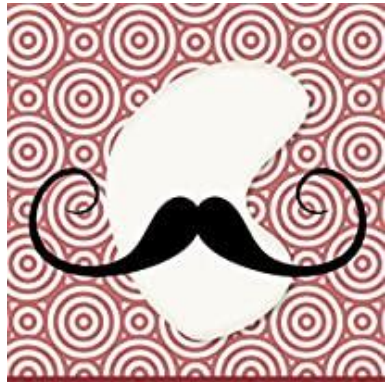

La malédiction

du bandit moustachu

Irina Teodorescu

Rentrée Gaïa

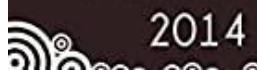
deux mille.

Dès lors, pour conjurer une réalité qui la dépasse ( « ces choses que je ne connais pas »), l'unique travail de la narratrice consiste en cette jubilation qui témoigne de la suprême liberté dont bénéficie son écriture. « Bien entendu - écrit-elle -, on peut aller loin comme ça, à imaginer des jours meilleurs qui auraient existé dans un passé hypothétique, mais après tout, pourquoi pas ?»

Rajoutons à cela une certaine bienveillance, comme une délicate complicité entretenue par une omniprésence auctoriale qui a ceci de particulier, c'est qu'elle devient une proximité visuelle qui permet à la narratrice d'assister à la naissance de son histoire : « J'ose même supposer - et cela malgré sa silhouette grise et épaisse qui s'affaisse sous mes yeux alors que j'écris ses lignes [...] ».

Rien de plus facile pour comprendre que c'est dans cette proximité avec ses personnages qu'Irina Teodorescu puise sa capacité de concentrer en quelques lignes de surprenants et exhaustifs portraits, surtout lorsqu'il s'agit de son personnage fétiche, le fameux " bandit moustachu », mélange de fakir indien et de solitaire justicier de Valachie. Le vrai trésor de son apparence loufoque, c'est sa « longue moustache, si longue qu'il la trempe souvent dans la sauce de son plat préféré - une bouillie de haricots blancs - traditionnel chez les paysans de cette contrée lointaine ». Son appétit gargantuesque devient curieusement la marque de sa bonté et, parmi les paysans à qui il rend justice, " personne n'a l'idée de le livrer aux forces de l'ordre ». Mais ce qui le rend encore plus singulier est l'utilisation de ce même trophée comme garde-manger fétide, au risque de faire fuir les âmes sensibles qu'il croise. Sauf que « les paysans démunis à qui il rend justice ne remarquent point son odeur répugnante, personne ne se demande si l'homme ne néglige pas un peu son apparence [...] ». 
Face à ce moustachu sans nom que le hasard fait pousser la porte du salon perdu de ce barbier villageois, se trouve Gheorghe Marinescu, client habitué de la boutique, " petit bourgeois du coin », encore plus fier « de la beauté de la partie inférieure de son visage », car plus raffinement coupée et entretenue que celle portée par ce rustre porteur d'insalubres moustaches.

C'est donc chez ce barbier que commence l'histoire de ces deux hommes aux destins désormais entremêlés sur plusieurs générations. En cause, la malédiction que profère ce bandit devenu victime d'un plus malin que lui : tout premier garçon de la famille devra mourir tragiquement, et cela jusqu'à la fin du siècle. Gheorghe Marinescu n'a que faire de ces sornettes, il avait attiré le bandit sous prétexte d'une vente improbable, l'avait laissé croupir jusqu'à le faire crever de soif et de faim dans sa cave et s'était emparé de son trésor qui allait servir à son émancipation : " Quelques mois plus tard [...], il se rase le visage, décide de porter monocle, et entreprend d'agrandir sa maison ». Propriétaire terrien modeste par héritage, il va donc devenir un homme honorable et prospère, peu importe par quels moyens. Sauf que la malédiction du bougre justicier ne tarde pas à s'abattre sur lui, car il est en effet le garçon aîné de la famille : à l'âge de vingt-sept ans, lors d'une partie de chasse, Gheorghe meurt à cause d'une balle perdue.

Que faudra-t-il dorénavant faire pour conjurer le sort jeté sur la famille Marinescu?

Dans ce village où religion et superstition font bon ménage, Lila, la femme de Gheorghe, paie deux messes à la mémoire de son mari (dont l'âme brûle déjà en enfer), messes qui se révèlent en fin de compte inefficaces devant le pouvoir de la malédiction qui va les poursuivre : à l'âge de vingt-deux ans, leur fils meurt " dans un terrible accident de carriole ». S'ensuit la mort du fils aîné de Maria la Cadette qui meurt, quant à lui, dans un accident de fiacre.

Ainsi, dès les premières pages du livre, nous apprenons que la force de cette malédiction est plus redoutable que l'on ne croit, surtout lorsque les femmes s'amusent à leur tour à jouer avec le sacré. C'est le cas de Maria la Cochonne, qui entreprend un pèlerinage mouvementé en Terre Sainte mais qui se permet quelques libertés par rapport à la conduite d'une ardente pénitente, à tel point que ses prières restent sans réponses à ses lamentations et finissent par rendre la situation encore plus grave.

Heureusement qu'avec le temps, le souvenir et la menace de la faute originelle de l'ancêtre Gheorghe vont s'estomper, permettant au récit de s'élargir, d'échapper à l'urgence d'un dénouement déjà annoncé et laissant les personnages profiter de cette bénéfique respiration narrative pour prendre de l'essor. Car, au fond, le souvenir de tous ces drames pourrait bien s'atténuer et s'accommoder avec les époques, plus stoïques 
au fur et à mesure du temps qui passe et moins crédules aux improbables légendes anciennes.

Cela permet au récit de s'humaniser, de survoler d'autres territoires et d'autres époques, et de permettre aux personnages de se découvrir plus amplement. Voyages en Europe de l'entre deux-guerres et histoires d'amour, politique et mariage par intérêt ou par amour, fidélité et trahisons sont autant de thèmes qui désormais prennent place dans l'économie du roman d'Irina Teodorescu. Certaines précisions offrent au lecteur avisé des indices sur les époques qui marquent le cours de l'histoire roumaine - celle de la Grande Guerre, celle de la montée du fascisme, de l'antisémitisme et des rafles, de la Seconde Guerre et de l'arrivée du communisme, etc. - et des changements qu'elles opèrent dans les comportements des Marinescu à travers toutes ces années.

Et, si les hommes, surtout les aînés de la famille, semblent condamnés d'avance, que dire des femmes qui traversent comme des étoiles délicates, souvent comme de vraies comètes, ce monde impitoyable où la folie et l'excentricité semblent prendre le dessus sur la normalité et le droit à l'amour dans une descendance condamnée à la " folie triste », l'autre nom de la dépression ? Elles finissent par s'enfermer dans une maternité blessée comme Agripina, ou dans une étrangeté proche de la sorcellerie, comme Ana la Belle Sorcière, avec ses remèdes universels.

Malgré toute cette tension dramatique, il serait faux de croire que $L a$ malédiction du bandit moustachu est par excellence un récit tragique, même s'il est traversé de long en large par une fatalité pesante qui finit par laisser croire en un irréconciliable fatum qui régit la vie de ses personnages.

La sensibilité, même timidement affirmée, de cette jeune et talentueuse romancière franco-roumaine, arrive à percer l'abondance et l'étrangeté du fil narratif de ce récit. Car au fond, Irina Teodorescu fait partie de ces êtres assoiffés d'amour dans sa forme la plus accomplie, celle de la liaison qui dure et qui défie le temps par une liaison pérenne, se regardant dans le miroir de l'attente de l'être rêvé. Elle semble connaître par cœur l'équation de l'engagement à deux et de ses écueils, celui où « elle [la femme] a toujours tenu bon et lui [l'homme], il a toujours lâché l'affaire au bout d'un certain temps, par paresse ou par pitié ou par dégoût et ne me dis par amour, car l'amour est absent de telles situations ».

Quoi qu'il en soit, il faut se réjouir du fait que cette sensibilité soit accompagnée d'une telle réussite littéraire qui porte au-devant de la scène une heureuse mixité d'univers et de thématiques témoignant de la proximité que les cultures française et roumaine entretiennent depuis toujours, sur un fond de francophonie, de dialogue et de tradition littéraire. 
Ce sont des gages suffisants pour souhaiter un long et prolifique chemin littéraire à cette jeune pousse qui vient greffer sa fraîcheur et sa joie de vivre sur le tronc magistral du dialogue culturel qui existe depuis si longtemps entre nos deux pays.

Il ne nous reste qu'à lui souhaiter bonne route et pleine réussite !

\section{Le bonheur comme une journée de solstice : Celui qui comptait être heureux longtemps, un roman d'Irina Teodorescu 3}

Nous avions quitté Irina Teodorescu déambulant au gré des malédictions et des fantômes : nous savons désormais que ces mêmes spectres sont capables de traverser avec autant d'agilité à la fois les murs lézardés de ses souvenirs et l'espace intime de son écriture. Son nouveau roman Celui qui comptait être heureux longtemps revisite le drame d'une famille anéantie par la disparition d'un fils tant aimé, sur fond de dictature, de privations, de menaces, de risque d'enfermement et de folie déshumanisante. Aucune arithmétique ne saurait donner sens à cette suite qui, au lieu de retenir ces malédictions, s'emballe dans une folie destructrice qui précipite les protagonistes dans une chute immanquable. Irina Teodorescu pose ainsi l'une des questions ontologiques les plus douloureuses, celle du prix à payer pour s'opposer à une force extérieure omniprésente, aveugle et dévoratrice qui se moque de la vie et la piétine.

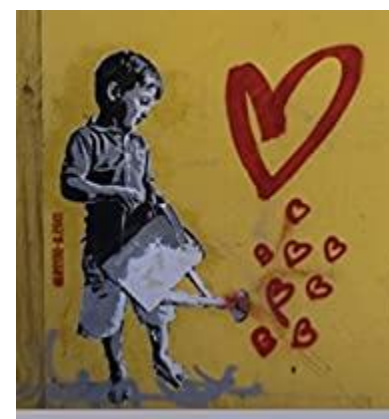

Celui qui comptait être heureux longtemps Irina Teodorescu

Le ton est donné dès le début, la tension narrative devient rapidement irrespirable et prend des couleurs de tragédie grecque avec, en trame de fond, un Prométhée enchaîné et blessé à mort par la dictature communiste. Dans cette atmosphère pesante, le seul moyen qui permet le déploiement du récit est une rhétorique capable d'atténuer ce vertige et d'extraire la sève de ce vécu plein d'une humanité souffrante. Ce choix en faveur d'un discours poétique envoûtant, jouant avec la sémantique et les consonances et transfigurant le réel en métaphores lénifiantes, agit comme un aimant qui happe et enchante le lecteur. La romancière d'origine roumaine prouve une fois de plus qu'elle possède une parfaite maîtrise de la langue française. Plus encore, son écriture prolonge ce que l'on a nommé dans les années '8o la littérature de dissidence de la diaspora roumaine. Irina Teodorescu bénéficie quant à elle d'une distance et d'une vision renouvelées grâce à un angle de vue générationnel nouveau, sans perdre pour autant en acuité de l'incrimination et en

3 Irina Teodorescu, Celui qui comptait être heureux longtemps, Gaïa Éditions, 214 p. 
persistance d'une mémoire encore vive, personnelle ou collective. Si à l'époque ces œuvres avaient valeur de stupéfiante révélation venant de derrière le Rideau de Fer, la nouvelle génération dénonce ce mal comme une maladie transmise par leurs parents et imprimée dans leurs gènes. Enfants d'un Tchernobyl idéologique, ils réclament justice pour les souffrances dont ils continuent à porter les stigmates.

L'histoire des Pol et Ala GO, une famille d'intellectuels bucarestois, commence avec la naissance, sous le bruit des bombes, de leur fils unique, Bo. Avec lui, l'Histoire avec une majuscule donnera naissance « du ventre de la guerre » à une « sœur jumelle [qui] grandissait et nourrissait des rêves de pouvoir » et qui portera le nom de la Nouvelle Société. La comparaison entre leurs deux destins satellitaires, tournant en sens contraire autour d'un présent indécis, va jusqu'à l'antinomie exemplaire, comme deux archétypes condamnés à s'opposer à jamais. " Après tout, nous sommes nés en même temps, elle et moi, moi et elle [...] » - reconnait Bo, en continuant à s'adresser directement à son interlocutrice imaginaire « notre premier cri, nous l'avons poussé ensemble, notre premier choc, sous les derniers bombardements ; j'ai l'impression que nous avons tété le même sein, que nous avons partagé le même bac à sable, que nous avons fait pas en nous tenant l'un à l'autre ». D'où vient alors ce sentiment affirmé d'une opposition irrévocable entre eux, et pourquoi Bo qualifie de " meurtrière », de « traîtresse et maligne » cette entité ?

Tout le fil narratif se construit à partir de cette image contrastée, qui s'étend à tout un peuple que Bo, le narrateur, qualifie de " poulets en batterie » qui vivent "sans éclat ». Quel est donc, sur ce fond de pénitencier social, l'avenir de cet homme " avide de beauté, buté et doué, joueur » ? Comme tous les jeunes de son époque, il aime la musique pop, les chansons de Timi Yuro, il aime les belles filles, comme l'énigmatique Irenn, il a des amis comme Dilo et Vass, il fait de brillantes études en électronique et se fait embaucher à l'Institut de Recherches Scientifiques. Là-bas, il connaîtra Di qui deviendra sa femme, et ce couple à qui le bonheur semble sourire espère, malgré tout, pouvoir être " heureux, longtemps, comme une journée de solstice ». Dans leur bonheur juvénile, ils ne remarquent pas la cruauté insidieuse de la machine à broyer leurs vies, à commencer par leur identité noyée dans la masse de formulaires à remplir, devenant chacun " un formulaire classé dans un dossier », un de plus dans ce pays sous dictature. Il faut tromper cette réalité, et se dire que même s'ils ne sont qu'un « délicieux caramel » broyé par la Nouvelle Société " aux dents en fer », prête " à mordre, à déchiqueter », ils échapperont à cette machine.

Bo et Di auront un enfant, un garçon, et leur bonheur sera au comble. Ils recevront un appartement plus confortable où la famille pourra s'épanouir. Sauf que le génie d'inventeur de Bo attire l'attention 
du général AN du Département de la Sécurité Civile et Politique de l'Etat et des Masses, le D.S.C.P.E.M. Un regard attentif se pose sur le jeune savant dont le travail intéresse au plus haut niveau. Il est surveillé et son activité scrutée de très près. Il perd la liberté d'agir et tous ses actes sont passés au peigne fin. À cela s'ajoute un drame familial qui s'abat sur le couple. Bo finit par ressembler de plus en plus à « un homme en morceaux [...] que personne ne peut recoller ».

On reconnaît là le drame de toute la génération d'après-guerre dans la Roumanie communiste livrées aux agissements de son régime dictatorial. Avec un extraordinaire sens du détail, Irina Teodorescu utilise le genre dramatique pour rendre visible l'atmosphère pesante des interrogatoires faits par les officiers du Département de la Sécurité. Bo sait que cette peur insidieuse durera pour toujours, il la portera de manière obsessionnelle et saura la reconnaître des années plus tard, même après la chute du régime. Ce sentiment - nous dit-il - est " exactement comme l'eau du fleuve, tous les jours ça passe sans passer ».

Comme lui, assis au bord du fleuve trouble de l'histoire récente d'un pays tant aimé et dont ils ne cessent d'implorer le majuscule Réveil, comme le dit l'hymne national, de nombreux amis de l'emblématique Bo implorent l'assainissement de cette eau à coup de patience et d'espoir. Eux aussi comptent « être heureux longtemps », le plus longtemps possible. Si seulement...

\section{Interview. Irina Teodorescu : « Je pense que toute forme d'écriture et de création est une recherche du sens de la vie $\gg 4$}

Après avoir franchi le pas de l'écriture en publiant en 2014 La malédiction du bandit moustachu, Irina Teodorescu publie cette année Les étrangères, toujours aux Éditions Gaïa. Les deux ouvrages sont écrits directement en français. Le détail a toute son importance car, arrivée à l'âge de 19 ans en France, cette jeune écrivaine ne parlait pas un mot de la langue de Molière. Rien d'étonnant, pourtant, pour ceux qui connaissent l'incroyable capacité d'un Panaït Istrati ou d'un Emil Cioran à faire de cette langue d'adoption une

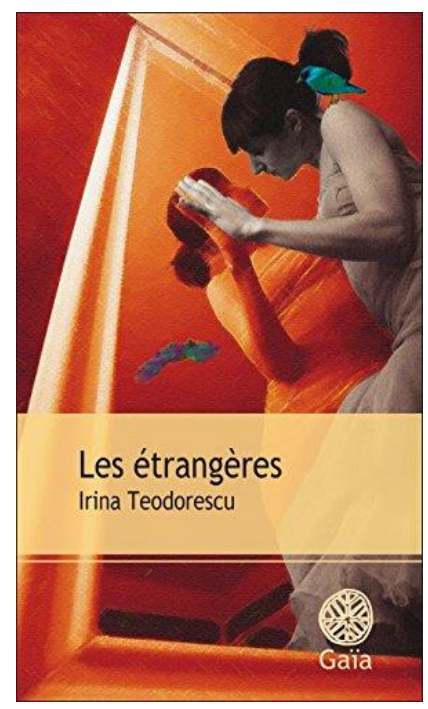
demeure à leurs interrogations et à leurs sentiments les plus intimes. En

4 Propos recueillis par Dan Burcea.

Crédits photo : (C) G. Fourrel

Irina Teodorescu, Les étrangères, Éditions Gaïa, 2015, 218 p. 
effet, n'était-il pas essentiel pour le philosophe du désespoir d'habiter une langue plus qu'une patrie ? Â son arrivée de Roumanie, Irina Teodorescu a dû refaire à ses dépens la même expérience, contribuant à son tour à retisser les liens d'une latinité qui, pour se régénérer, convoque dans chaque génération ses meilleurs talents. Cette transmission est aussi sublimée dans l'univers thématique de son œuvre. En effet, si La malédiction du bandit moustachu tire son inspiration du monde des haïdouks d'Istrati, Les étrangères est plus enclin à la réflexion philosophique cioranienne, voulant « montrer l'invisible du monde à ceux qui ne savent pas regarder ». L'antiphrase de ce deuxième titre répond plus que tout au besoin de définir une identité qui se cherche plus qu'une absence de racines ou une quête perdue d'avance.

C'est ainsi, à mon sens, qu'il faut regarder cette jeune écrivaine, considérée déjà par la critique comme une étoile montante des lettres françaises 5 et qui est loin de se laisser enfermer dans des clichés ignorant ses mérites et détournant le regard de son talent.

Seriez-vous prête à vous reconnaître dans cette tradition littéraire qui vous inscrit dans la lignée d'un Panait Istrati ou d'un Emil Cioran?

Reconnaître la tradition littéraire, oui. D’ailleurs je pense qu'il s'agit tout simplement du transfert d'un vécu semblable dans la littérature. J'ai une culture roumaine et je la mélange, dans la vie de tous les jours (y compris en cuisine, même si ce n'est pas mon territoire préféré) avec la culture française. C'est ce qu'il a dû arriver à pas mal de gens et parfois nous pouvons lire ce mélange dans la littérature. Dans ce sens, je crois être complètement comme Istrati ou Cioran ou Ionesco ou tant d'autres.

On peut peut-être citer d'autres écrivains français ou roumains qui vous ont servi de modèles.

J'ai des écrivains modèles oui, mais il s'agit - pour moi - de modèles de vie et non pas nécessairement d'écriture. C'est le cas de Simone de Beauvoir, que j'admire énormément pour son intelligence, sa finesse d'esprit. J'aime beaucoup son écriture aussi, le naturel de ses phrases, mais pour cet aspect je préfère les plumes plus sensibles, celles qui créent des images auxquelles je n'avais pas pensé mais que je trouve très justes. Par exemple Marguerite Duras. Ou, dans un autre registre, Bernard-Marie Koltes. Mircea Eliade. Elsa Morante. Siri Husdvet.

\section{Vous écrivez directement en français. Pourquoi pas en roumain?}

Le roumain est la langue de mon enfance. Et la Roumanie est le pays de mon enfance. Je crois que si j'écrivais en roumain, ce serait des livres

5 Voir le lien : http://www.arte.tv/magazine/metropolis/fr/irina-teodorescu-metropolis 
pour enfants (et en répondant à votre question cette idée me vient. Peutêtre que je devrais faire ça !)

Joséphine Zandana, votre hérö̈ne, vit d'ailleurs entre ces deux mondes, entre la Roumanie de l'époque communiste et post-communiste et la France. Issue d'une famille francoroumaine, peut-on dire qu'elle est l'image même de cette mixité ?

Je ne sais pas. Peut-on dire que nos enfants sont l'image même de deux parents mélangés ? Pas vraiment... Je pense que Joséphine existe, en tant que personnage. Hors de ces deux pays. Elle existe tout simplement, elle incarne un désir de vivre et de créer, une étrangeté, une solitude, une façon d'aimer. Enfin, je l'espère!

Quel sens peut avoir pour elle le « chez-nous « qui ne se trouve ni en France, " château rempli de richesses », ni en Roumanie, pays où le gris et la tristesse sont partout?

Aucun sens et c'est pour cette raison que le livre s'intitule Les Étrangères. Je ne pense pas que l'homme soit intrinsèquement étranger. Cette notion nous vient en même temps que la conscience de la nudité. Un enfant de 4 ans peut se balader nu et ni lui, ni les autres, ne seront gênés. Un enfant de 4 ans roumain peut aller en France et ne pas se sentir étranger. Ce sont des notions qui arrivent plus tard, donc des notions culturelles. Joséphine est perturbée oui, car sa sensibilité et son intuition sont trop présentes. Elle ne comprend pas vraiment les autres. À cause de ce fait elle devient, elle, intrinsèquement étrangère. Elle ne peut donc pas parler d'un chez-elle.

À travers ces souvenirs, la fragrance sucrée d'un parfum va la suivre dans son voyage à travers les frontières de ces deux mondes.

C'est le parfum de son rêve d'enfance. Nous avons tous, je crois, une petite bouteille comme celle de Joséphine.

Nadia, la petite amie de Joséphine, laisse s'exprimer son admiration pour Paris. À son arrivée de Bucarest, elle est éblouie par sa lumière, par ses ponts, par les terrasses et les constructions. Elle tombe amoureuse de cette ville. Doit-on voir votre vécu personnel derrière cette voix ?

Oui, un peu. Je suis tombée sous le charme de cette ville dès que j'y ai mis les pieds. Aujourd'hui je n'y habite plus (je vis à Rennes), mais Paris restera dans mon cœur la ville que je préfère.

Et puis il y a la langue française, comme un élixir enivrant de beauté que l'on absorbe à grosses gorgées dans une longue liste où l'énonciation coule d'elle-même, laissant transparaître la fragrance des mots...

Oui, j'espère que j'ai réussi ce passage, car il est important pour moi. Je crois que pour un français de souche il n'a pas beaucoup d'intérêt. 
Cependant à travers Nadia je parle de la langue française mais aussi de la langue de l'amour. Surtout du premier amour. J'ai entendu une fois dans une émission à la radio qu'il y a des fréquences différentes selon les langues. Je crois que lorsqu'on est amoureux, on est entièrement sur une autre fréquence.

Devenue photographe célèbre, Joséphine connaîtra le succès, quittera Bucarest pour Paris et entraînera avec elle Nadia, la danseuse, dans une histoire d'amour fusionnel.

Oui, je voulais parler dans ce livre d'une relation fusionnelle. $\mathrm{Au}$ départ ce n'était pas forcément l'amour. J'allais parler d'amitié, ou d'un lien qui peut se créer lorsqu'on a les mêmes projets et la même énergie. Mais je trouvais que l'amour servait mieux mon propos. Introduire un concept plus compliqué voulait dire m'éloigner du centre de mon propos.

Peut-on placer ces deux personnages en contradiction évidente, Joséphine voulant photographier l'invisible, tandis que Nadia voulait « rendre invisible ce qui était trop visible »? Sont-elles deux faces opposées d'une même personne?

Peut-être bien. Je pense que l'on peut y voir surtout une métaphore de la création artistique. Son recto et son verso.

Par la voix de Joséphine, vous définissez la vie comme « un temps, une courte occasion de trouver un sens et de le transmettre ». Peut-on définir votre roman comme un questionnement sur le sens de la vie ?

Bien entendu. Je pense que toute forme d'écriture et de création est une recherche du sens de la vie. Mais Joséphine est plus optimiste que moi : elle pense qu'on peut trouver un sens et qu'on peut même le transmettre. Pour ma part (et pour le moment) je considère la vie comme une courte occasion de chercher un sens. C'est déjà beaucoup. Et je me rends compte que j'aurais dû devenir chercheur en biologie.

Ce thème sur le sens de la vie est-il une problématique essentielle de votre réflexion littéraire? Le gardez-vous comme thème pour vos futurs projets littéraires?

Oh, du coup je pense que j'ai répondu plus haut à cette question. Je crois que c'est le thème de tout projet (littéraire ou pas) et donc oui, je le garderai, même s'il sera peut-être un peu plus déguisé.

6. Rentrée littéraire 2019 - Interview Irina Teodorescu : « J'écris sur ces événements-là comme j'écrirais sur n'importe quel autre, j'écris selon ce qu'ils m'évoquent ${ }^{6}$

${ }^{6}$ Interview réalisée par Dan Burcea

Crédits photo : Pascal Ito (C) Flammarion

Irina Teodorescu, Ni poète ni animal, Editions Flammarion, 2019, 224 p. 
Parmi les livres attendus de cette rentrée littéraire, celui d'Irina Teodorescu, $\mathrm{Ni}$ poète ni animal, a une importance particulière pour ceux qui s'intéressent à l'univers romanesque de cette auteure franco-roumaine traversée par les bouleversements de l'histoire contemporaine de son pays d'origine. À trente ans de distance de la chute du communisme, Carmen, son héroïne, qui n’a que 10 ans à cette époque, s'interroge sur la véritable nature de cet événement. Journal de l'année 1989, dernière année de la dictature communiste en Roumanie vécue par une enfant qui scrute les comportements de ceux qui l'entourent, le livre d'Irina Teodorescu déborde à la fois de lucidité et de poésie, de nostalgie et de candeur.

$\mathrm{Ni}$ poète ni animal est votre quatrième roman écrit en français. Avons-nous raison d'affirmer que le français est devenu définitivement votre langue littéraire ?

C'est ma langue d'écriture en effet, mais elle n'a pas eu à le devenir : si l'on omet mes poèmes de pré-adolescente à la gloire de ma maîtresse, je n'ai jamais écrit qu'en français.

Y a-t-il un lien entre votre précédent roman Ceux qui comptaient être heureux longtemps et celui-ci, qui est écrit sous forme d'un journal de la dernière année du régime des Ceaușescu?

Oui, les deux romans ont affaire au régime de Ceaușescu mais le point de vue est très différent. Celui de ce nouveau roman est principalement à hauteur d'enfant. Effectivement, ce qu'il a du journal (intime), c'est une certaine chronologie, son aspect quotidien et la forte subjectivité de ce qui y est narré.

Vous donnez la parole à trois générations de femmes : Dani, la grand-mère, Ema, la mère, et Carmen, la narratrice, qui n'a à l'époque que 10 ans. Aviez-vous besoin de ce regard frais pour construire votre récit ? Pourquoi cette voix d'enfant?

C'est d'abord en raison de mes propres souvenirs de cette époque, que j'ai convoqués pour l'écriture, puisque j'avais moi-même 10 ans. Mais surtout parce que la vérité documentaire ne m’intéresse que partiellement, et que d'autres font cela bien mieux que moi. Nous vivons dans une culture de la rationalité et de l'exactitude qui ne cesse de montrer ses limites, là où l'on croyait pourtant voir venir la disparition du « faux ». Mon matériau à moi n'est pas l'information, c'est la sensation, le 
détail anodin, l'infra-sensible : je juge même que c'est par là, essentiellement, que l'on peut espérer effleurer la vérité d'un événement.

Alors j'avais besoin, oui, d'une voix d'enfant pour parler de la révolution qui approche, j'avais aussi besoin de la voix d'une folle et de celle d'une adulte responsable - d'elle-même et d'autrui. Quant à savoir laquelle est la plus pertinente des trois, je laisse chaque lecteur et chaque lectrice juge.

En Roumanie, le peuple vit une vie paisible, assis sur l'or : « ici, tout est en or, le blé est en or, l'époque est en or », proclame l'un de vos personnages qui ne fait que répéter en réalité des paroles de la propagande de l'époque. Que retient votre narratrice de cette époque et comment en parle-t-elle ?

Que retient-on de son enfance? On peut se raconter, après, que l'on a été malheureux ou heureux, selon des critères extérieurs de richesse ou de liberté. Carmen pourrait se dire qu'elle a été chanceuse, qu'elle a vécu du bon côté de la tyrannie ou que ça n'était finalement pas si terrible. Elle pourrait en tirer des conséquences politiques aujourd'hui. Mais la vérité, c'est que c'était une enfant et que c'est la seule enfance qu'elle a connue. Elle a été une enfant aimée, inquiète, rêveuse... À moins qu'on ne les en sorte par la violence la plus abjecte, les enfants vivent dans un monde qui échappe très majoritairement aux adultes, fussent-ils des tyrans.

Dans le cadre de votre journal mensuel de l'année '89, le mois de décembre est le plus important : c'est le moment de l'éclatement des événements de Timișoara et de Bucarest, la fuite du couple présidentiel et le dénouement du 25 décembre. Comment écrit-on sur ces événements, trente ans après ?

C'est un événement qui sert d'épine dorsale à mon histoire, il en est à la fois le décor et la métaphore. J'écris sur ces événements-là comme j'écrirais sur n'importe quel autre, j'écris selon ce qu'ils m'évoquent. Je fais bien sûr des recherches. Des recherches documentaires, publiques. Des recherches privées : des témoignages, des discussions. Des recherches intimes : souvenirs, choses écrites, photographiées, enregistrées de l'époque. Et puis après, c'est le jeu de la fiction !

L'histoire de la Roumanie contemporaine est-elle suspendue à ce dilemme shakespearien : révolution ou coup d'État ? C'est en tout cas une interrogation que vous posez à la fin de votre livre.

Ce n'est pas vraiment moi qui pose cette question mais, comme vous le précisez, c'est une interrogation qui parait hanter l'histoire roumaine, et dont le roman n'est qu'un reflet. Je ne suis pas certaine que la Roumanie contemporaine se porterait mieux si elle avait la réponse à cette question, je ne suis pas sûre que le problème soit cette énigme-là, mais 
plutôt ce qui a suivi malgré la démocratie : coup d'état ou révolution, il se trouve que les urnes ont mis les mêmes au pouvoir.

Devenue avocate en France, Carmen garde ses souvenirs comme un bien très précieux de joies et de douleurs. Le mot d'ordre reçu de son ami poète est « repoétise-toi ». Croyez-vous que cette belle injonction soit le meilleur remède contre les incongruités de l'Histoire?

Bien sûr. La vérité c'est qu'on peut facilement rire de la naïveté des poètes, mais que jamais l'on a eu - collectivement - comme espèce - la force et le courage d'essayer leur solution : que chacun.e se (re)poétise, en priorité, devant toute autre considération. Je crois que les « incongruités de l'histoire », si par là vous entendez les faits des hommes qui causent des souffrances absurdes, ne sont pas les fruits du hasard, elles sont la preuve que nous sommes - collectivement - un animal immature. Nous choisissons - collectivement - médiocrement, et je pense que seul le manque de poésie peut expliquer ces choix médiocres massifs à répétition. Soit ça, soit nous sommes la plus masochiste et suicidaire espèce du vivant que cette planète ait connue, et les poètes - si peu rationnels, si peu exacts - en sont les bugs.

\section{lancement? \\ Que peut-on souhaiter à votre roman en cette période de} Beaucoup de lecteurs et de lectrices, ouvert.e.s aux pas de côté. 